\title{
THE EDUCATION GENDER GAP AND THE DEMOGRAPHIC TRANSITION IN DEVELOPING COUNTRIES
}

\author{
Nguyen Thang Dao \\ Julio Dávila \\ Angela Greulich
}

Revised August 2020

December 2019

The Institute of Social and Economic Research

Osaka University

6-1 Mihogaoka, Ibaraki, Osaka 567-0047, Japan 


\title{
The Education Gender Gap and the Demographic Transition in Developing Countries*
}

\author{
Nguyen Thang Dao ${ }^{\dagger}$ \\ Julio Dávila \\ Angela Greulich ${ }^{\S}$
}

August 3, 2020

\begin{abstract}
This paper explores, theoretically and empirically, the role of the declining gender gap in education in the demographic transition and the emergence of modern economic growth. Specifically, the paper develops a model in the tradition of the unified growth theory that captures and interconnects the key empirical features of the demographic transition, the decline in gender gap in education, and the transition to sustained growth across less-developed economies. The mechanism on which the model relies comprises several interplaying components. First, technological progress reduces housework time through the creation and diffusion of labor-saving home appliances, which frees women's time for childrearing, resulting in an initial increase in fertility, as well as in labor-force participation. Second, due to the possibly higher female labor-force participation as housework time decreases, households invest relatively more in their daughters' education, given its higher return following the initial imbalance. This improves gender equality in education and increases the opportunity cost of childrearing, which leads to a subsequent decrease in fertility. Third and finally, the decrease in the education gender gap through higher investment in daughters' education increases average human capital, thus accelerating technological progress in turn. This reinforcing loop results in the transition to a new fertility regime and accelerated economic growth. We provide the empirical confirmation of the model's predictions using data from developing countries in the late 20th and early 21st centuries.
\end{abstract}

Keywords: Unified growth model; gender inequality; demographic transition; developing countries.

JEL Classification: J11, J13, J16, O11, O40.

\footnotetext{
${ }^{*}$ We thank the editors of the journal (Oded Galor and Madeline Zavodny), and four anonymous referees for providing helpful comments and suggestions. We also thank David de la Croix, Cuong Le Van, Sascha O. Becker, and David N. Weil for helpful discussions and encouragements. Earlier versions of this paper were presented at several seminars and conferences at the Universite catholique de Louvain, MCC Berlin, Vienna Institute of Advanced Studies, Catholic University of Lisbon, University of Warwick, University of Göttingen, and Osaka University. We have benefited from the comments and suggestions of participants. Funding from an MIS Ulysse research grant from the Belgian F.R.S.-FNRS is acknowledged. The first author would like to acknowledge the supports from the Japan Society for the Promotion of Science (JSPS) KAKENHI Grant-in-Aid for Scientific Research JP15H05728 and from the International Joint Research Promotion Program (Osaka University). The scientific responsibility is ours.

$\dagger$ Corresponding author. Institute of Social and Economic Research, Osaka University, 6 - 1 Mihogaoka, Ibaraki, Osaka 567-0047, Japan; Leibniz Institute of Freshwater Ecology and Inland Fisheries, Müggelseedamm 310, 12578 Berlin, Germany; and Mercator Research Institute on Global Commons and Climate Change, Germany. Emails: daonguyen@iser.osaka-u.ac.jp and dao@igb-berlin.de.

¥School of Sciences and Humanities, Nazarbayev University, email: julio.davila@nu.edu.kz; and CES, Université Paris 1 Panthéon Sorbonne, 106-112 Boulevard de l'Hôpital, 75647 Paris, email: julio.davila@univ-paris1.fr.

$\S$ OSC, Sciences Po Paris, 27 rue St. Guillaume, 75007 Paris, France. Email: angela.greulich@sciencespo.fr.
} 


\section{Introduction}

This paper explores, both theoretically and empirically, the role of the declining education gender gap in the demographic transition and the emergence of modern economic growth. The paper develops a model in the tradition of unified growth theory that captures and interconnects the key empirical features of the demographic transition, the decline in gender gap in education, and the transition to sustained growth across less-developed economies. In order to do so, and to explain some stylized facts from developing countries in the late 20th and early 21st centuries, we provide a new mechanism. Specifically, we show how the reduction of housework time due to technological progress operates through its interaction with households' education and fertility choices affecting the transition to a lower fertility and sustained growth, the reduction of earnings and human capital gender gaps, and the increase of female labor market participation.

Indeed, the generalization of home appliances in the 20th century reduced women's housework burden by decreasing housework time, freeing women's time for childrearing and leading to an initial increase in fertility, as well as in labor market participation. In turn, foreseeing higher labor market participation, parents invested relatively more in their daughters' education to increase their income, as well as to improve their bargaining position in the marriage market and as insurance against divorce. This improved gender equality in education. The subsequent increasing opportunity cost of childrearing then led to a decrease in fertility. In addition, the improvement in gender equality in education accelerated technological progress as it raised the average human capital in the economy, leading to the creation and diffusion of additional time-saving home appliances. The resulting reinforcing feedback loop thus generated a fertility transition along with accelerated economic growth.

This paper combines and goes beyond Galor and Weil (1996, 2000), Greenwood et al. (2005a, b) and Soares and Falcao (2008), thus complementing the literature on 19th century demographic transitions ${ }^{1}$ in the West (see Galor and Weil 2000, Galor and Moav 2002, Hansen and Prescott 2002, Doepke and Tertilt 2009, Cervellati and Sunde 2015, and recently Dao 2016, among others). It then seeks to explain the 20th century fertility transition of developing countries. Indeed, compared to that of the West, the demographic transitions in Asia, North Africa, and Latin America started around a century later at much lower per capita GDP, with fertility falling faster and from higher rates, prompting the search for alternative explanations. Consistent with unified growth theory (Galor 2011), our model highlights the role of technological progress and its impact on fertility and human capital formation in the demographic transition. However, unlike unified growth theory, in which the child quantity-quality tradeoff is induced by the gradual increase in the rate of technological progress, as was the case in the current developed economies, we focus on the experience of less-developed societies, in which the demographic transition was influenced by other important impacts of technology. To explain this, our model instead proposes that the developing countries' transitions hinge specifically on the spread of

\footnotetext{
${ }^{1}$ A demographic transition refers to the passing from a high fertility and high mortality regime - including child mortality- to a low

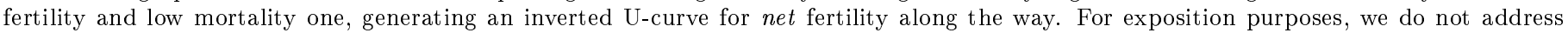

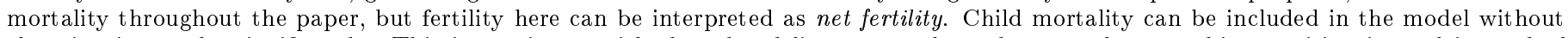

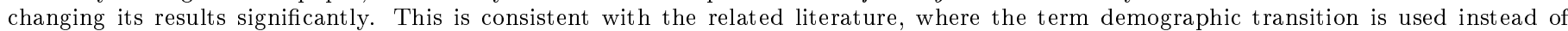

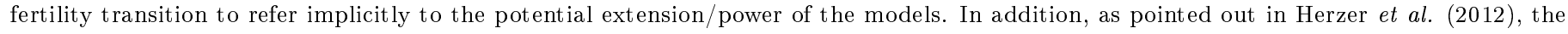

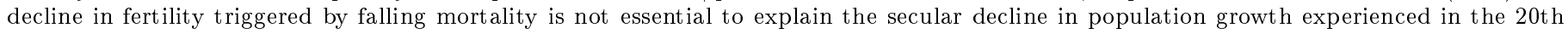
century. For a more comprehensive discussion on this, see Doepke (2005) and Galor (2012).
} 
home appliances, and its effects on households' fertility and education choices (see Greenwood and Seshadri (2005) and Greenwood et al. (2005a) for the US, and Mayers and Sathaye (1989) for their rapid spread in developing countries). ${ }^{2}$ The fall in fertility in developed countries took place instead, almost a century earlier, in the absence of a comparable creation and diffusion of home appliances, which was therefore understandably overlooked by the literature. Our model focuses precisely on the role of innovation in home appliances and their diffusion to explain the demographic transition of developing countries in the late 20th and early 21st centuries. ${ }^{3}$ Compared to that of developed countries, the literature on the demographic transition in developing countries is limited. The two cases differ mainly in the timings of the fall in fertility that are linked to the literature on comparative development, based on geographical factors (Dao 2016) and trade between industrial and less-developed countries (Galor and Mountford 2006, 2008).

The rest of paper is organised as follows. Section 2 reviews the literature. Section 3 introduces the model and its equilibrium dynamics. Section 4 analyses the evolution of the economy. Section 5 analyses its development to explain the stylized facts and discusses some extensions of the model. The empirical investigation is presented in Section 6, and Section 7 concludes the paper.

\section{Stylized facts and related literature}

The mechanism in this paper explains why, in the late 20th and early 21st centuries, developing countries have experienced a transition exhibiting the stylized facts illustrated in Figures 1, 2 and 3 below: a negative correlation between fertility and female-to-male education ratio; a positive correlation between per capita income and female-to-male education ratio; declines over time in the education and labor income gender gaps; a fertility transition as sustained economic growth takes off; an increase over time in the female formal labor market participation; and an eventual reversal in education across genders.

Our paper integrates two strands of economic growth and development literature: the demographic transition in unified growth theory, and technology and changing role of women. In the next subsections, we review these related literature.

\subsection{Demographic transition from unified growth theory perspective}

Demographic transitions have taken place across different regions of the globe since the first half of

\footnotetext{
${ }^{2}$ The share of households in Bangkok with refrigerators increased from $26 \%$ to $62 \%$, and from $63 \%$ to $95 \%$ in Taiwan in the period 1975 -

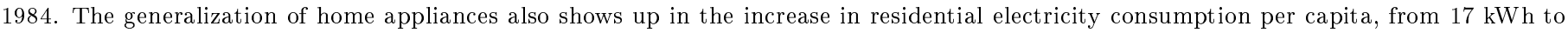

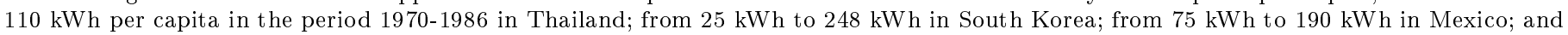
from $90 \mathrm{kWh}$ to $261 \mathrm{kWh}$ in Brazil (Mayers and Sathaye 1989).

The impact of technological progress on the economic role of women was even anticipated very early in the 20 th century, as shown by Thomas

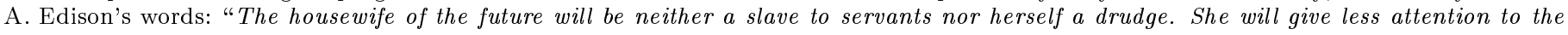

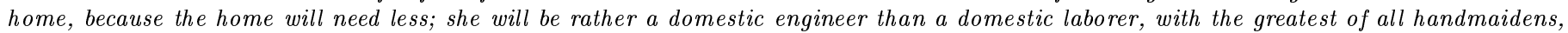

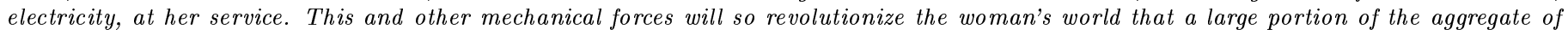

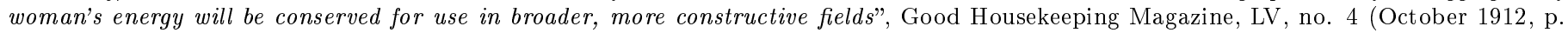
436). Quoted in Greenwood et al. (2005a).

${ }^{3}$ Recently, Bucci and Prettner (2020) also advance an endogenous growth model to consider the relationship between innovation and

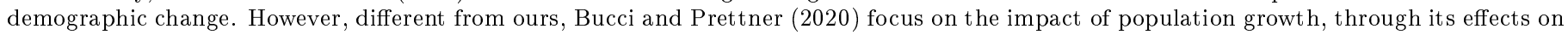

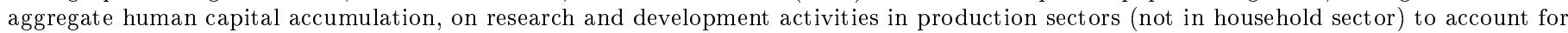

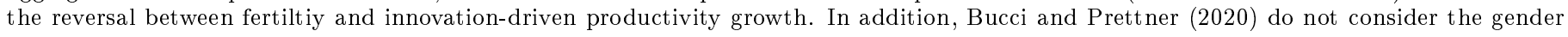
dimension of the problem while it is the main focus of our paper.
} 

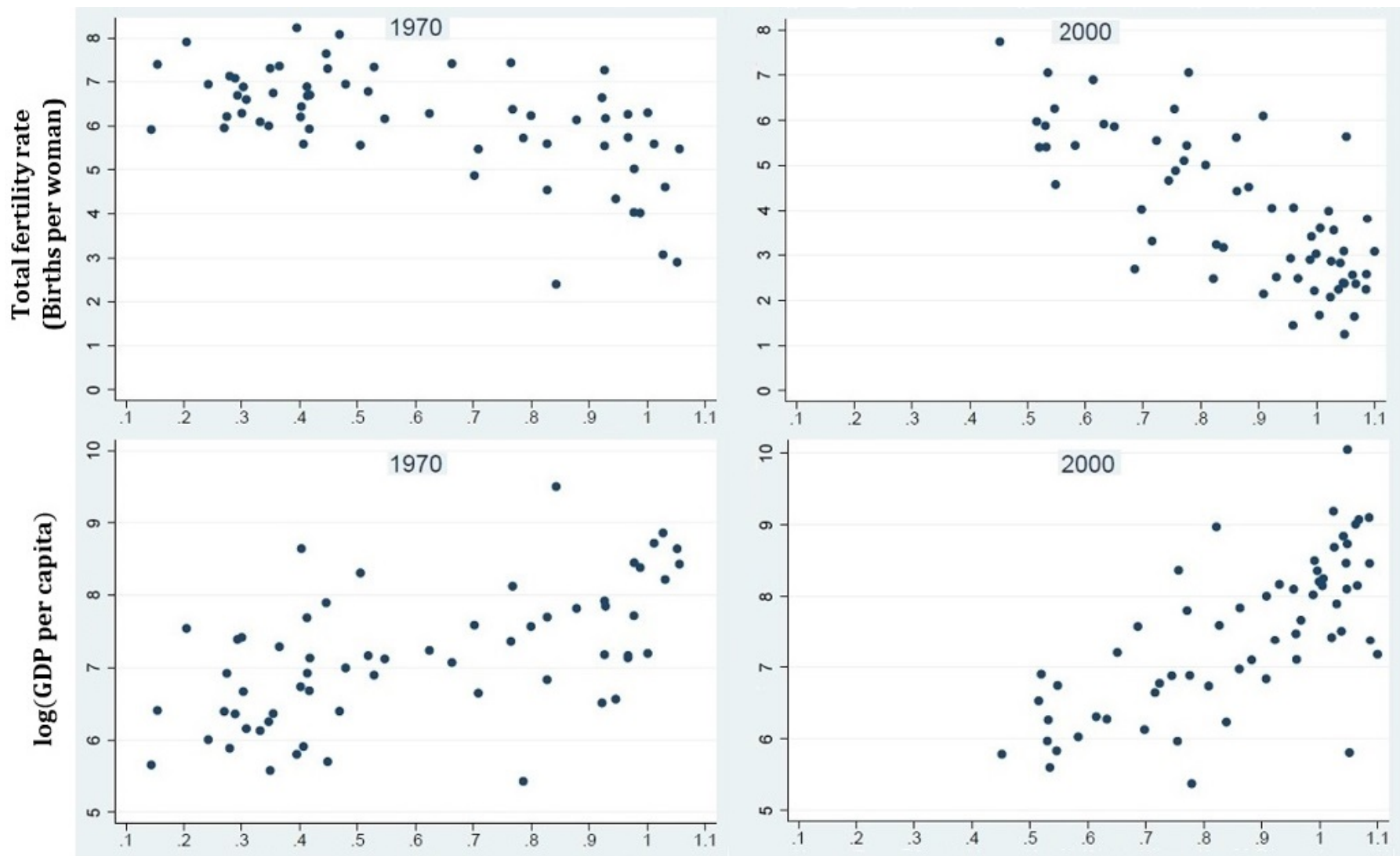

Ratio of female-to-male average years of schooling, ages 20 - 24

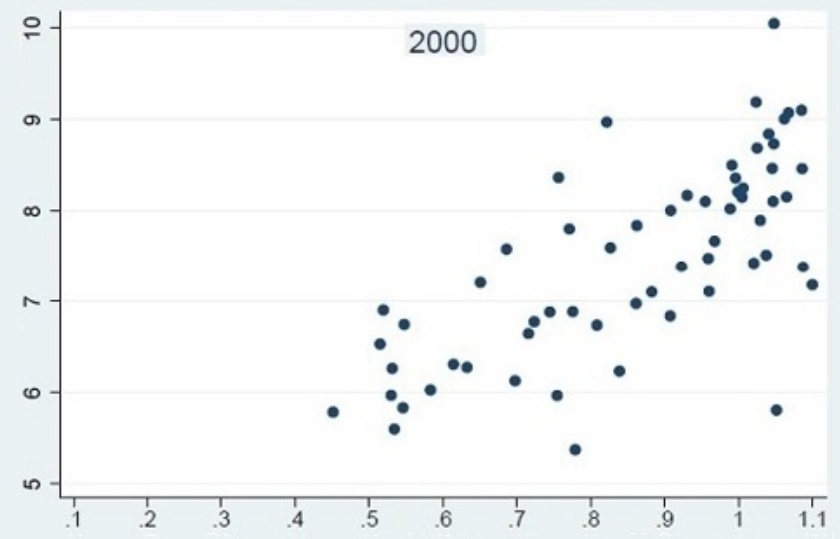

Ratio of female-to-male average years of schooling, ages $20-24$

Figure 1: Cross-country plots of fertility and per capita income (in US dollars) against gender equality in education (1970 and 2000). Each dot represents one country. The list of countries includes: Algeria, Argentina, Bangladesh, Belize, Benin, Bolivia, Botswana, Brazil, Burundi, Cameroon, Central African Republic, Chile, China, Colombia, Congo. Dem. Rep., Congo. Rep., Costa Rica, Cote d'Ivoire, Cuba, Ecuador, Egypt. Arab Rep., El Salvador, Gambia, Ghana, Guatemala, Honduras, India, Indonesia, Iran. Islamic Rep., Iraq, Jamaica, Kenya, Liberia, Malawi, Malaysia, Mali, Mauritania, Morocco, Nepal, Nicaragua, Niger, Pakistan, Papua New Guinea, Paraguay, Peru, Philippines, Rwanda, Senegal, Sierra Leone, South Africa, Sri Lanka, Sudan, Thailand, Togo, Tunisia, Turkey, Uruguay, Zambia, Zimbabwe. Source: WB WDI and Barro \& Lee (2013).

the 19th century. First in the West, and then across the developing world in the 20th century. It has both fostered the accumulation of production factors (physical and human capital), technological progress, and labor productivity, etc. as well as having been fostered itself by these very same factors and outcomes along the development process. Thus, the interactions between a demographic transition and all these factors have been studied extensively in the framework of unified growth models.

Indeed, the phenomenon of a demographic transition is one of the key features of the unified growth theory first advanced by Galor and Weil (2000) in their explanation of the development process from Malthusian stagnation to modern growth. Specifically, unified growth theory — Galor and Weil 2000, Galor and Moav 2002, Hansen and Prescott 2002, Cervellati and Sunde 2013, Dao 2016, among others - suggests that the technologically-driven increase in demand for human capital, and its effects on the children quality-quantity trade-off plays the central role in the demographic transition and, more generally, the transition to modern economic growth. This theory has been confirmed empirically by Becker and Woessman (2009), Becker et al. (2010, 2011), and more recently Fernihough (2017). Thus, the rise in demand for human capital and the decline in gender gap have been documented as 


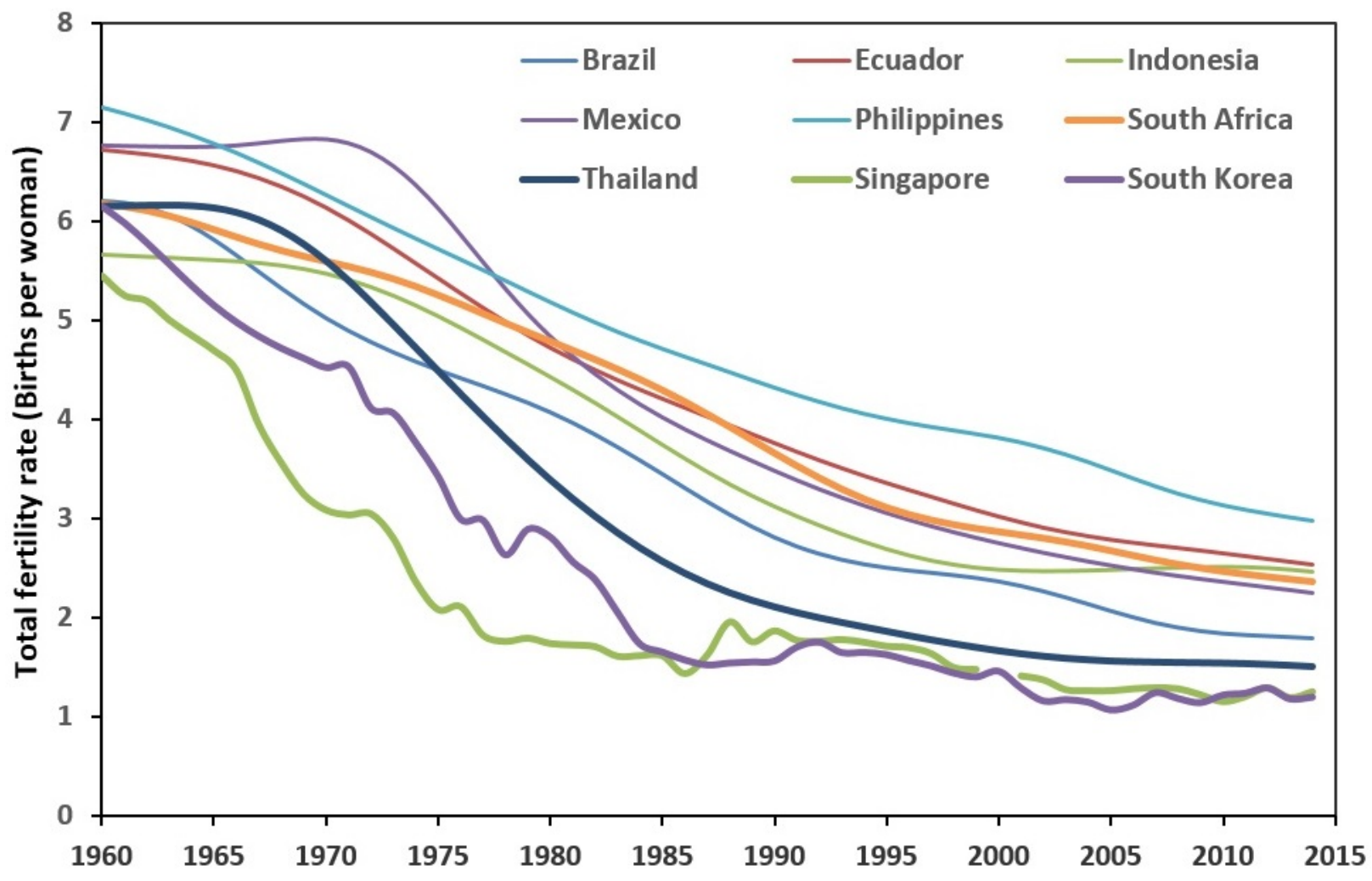

Figure 2: Fertility across countries (1960 - 2015). Source: World Bank (2020).

the major causes of demographic transition. ${ }^{4}$ Galor and Weil (1996) advanced an alternative unified growth model showing that the decline in the wage gender gap - resulting from physical capital being more complementary to women's labor than to men's - plays a central role in generating a decline in fertility too.

In this tradition, our model contributes a novel mechanism to explain, in particular, the demographic transition experienced by developing countries since the second half of the 20th century. Specifically, we focus on the role played by innovations in, and diffusion of, time-saving technologies for housework in the decline in gender gap, as well as the feedback of the latter into technological progress. In a way that is complementary to the traditional unified growth theory, we therefore put the gender gap at the center of the analysis. Indeed, complementing the approach in Galor and Weil (1996) that considers the decline in the wage gender gap to be due to the accumulation of physical capital, we show that technological progress also plays a crucial role in reducing the human capital gender gap, improving thus income equality across genders. Alternatively, Soares and Falcao (2008) suggest that the narrowing of the wage gender gap and the increase in female labor supply follow from a demographic transition initially triggered by improvements in life expectancy and a decline in fertility, which complements rather than contradicts the mechanism put forward in our paper.

\footnotetext{
${ }^{4}$ Other factors such as the increase of income per capita (Becker 1960, Becker and Lewis 1973), the decrease of infant and child mortality (Kalemli-Ozcan (2002, 2003), Tamura 2006, Tamura et al. 2016, Tamura and Simon 2017), and the old-age security (Neher 1971, Caldwell 1976, Boldrin and Jones 2002) have been showed to be inconsistent, on their own, with the data, and therefore are considered as reinforcing minor factors rather than main factors in explaining the demographic transition. For a more comprehensive overview, see Galor (2011).
} 


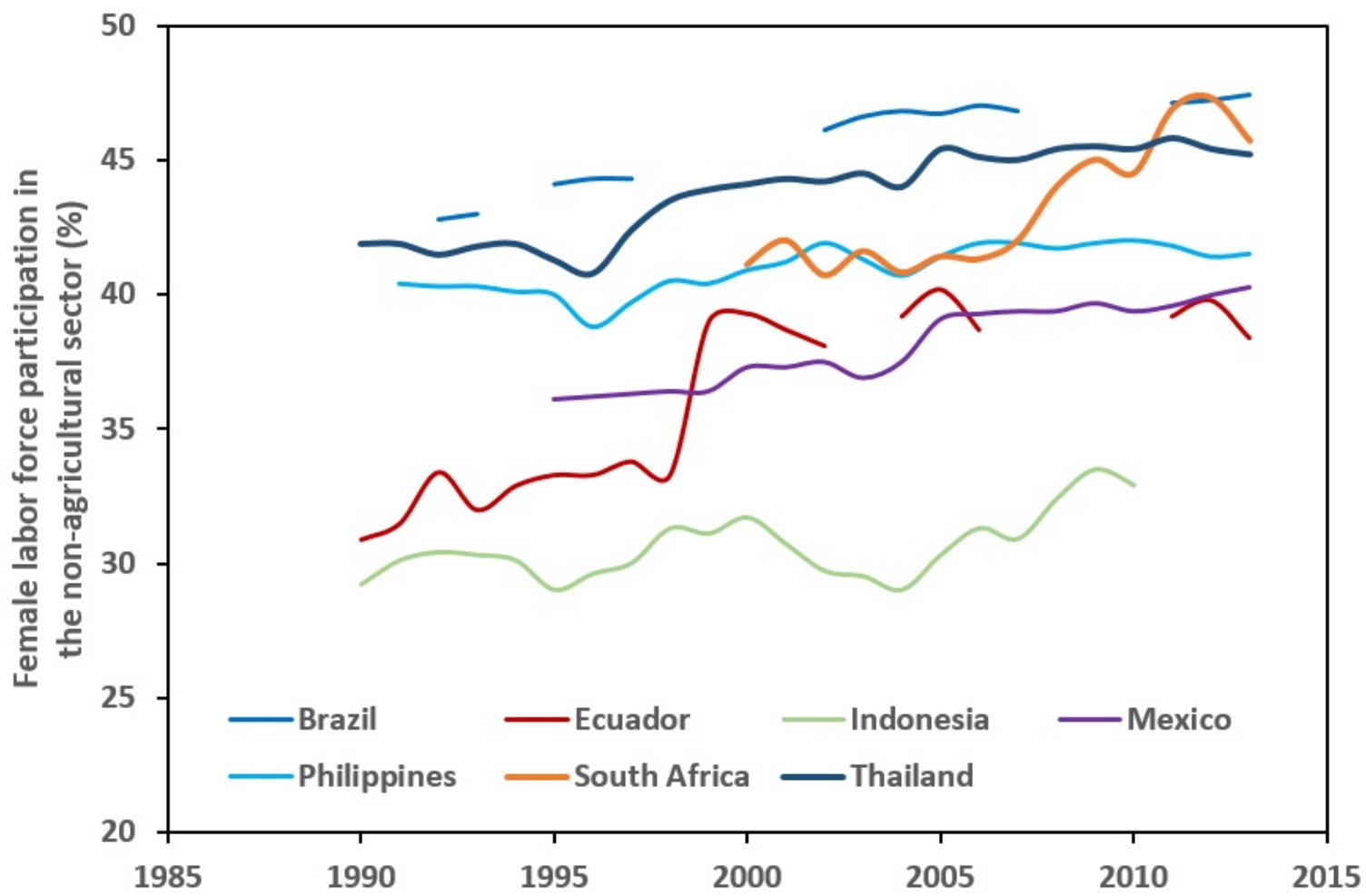

Figure 3: Female labor force participation in non-agricultural sector. Source: WB WDI.

\subsection{Technology and the changing role of women}

In addition to inserting itself in the child quantity-quality tradeoff tradition (Becker 1960, Becker and Lewis 1973, Galor and Weil 2000, Tamura 2006, Hazan and Zoabi 2015a), our paper relates to the literature on technology and the changing role of women in the household and society (Galor and Weil 1996, Greenwood and Seshadri 2005, Greenwood et al. 2005b, Soares and Falcao 2008, Bloom et al. 2009, Doepke and Tertilt 2009, De la Croix and Vander Donckt 2010, Duflo 2012), as well as the demographic transition (Galor and Weil 2000, Hansen and Prescott 2002, Doepke 2004, Cervellati and Sunde 2015, among others).

Greenwood et al. (2005b) study the link between home appliances and the baby boom in developed countries after World War II. Home appliances have reduced the marginal cost of childrearing - higher in developed countries - and have thus increased fertility as the depressing effect of rising incomes is more than offset. ${ }^{5}$ We focus instead on the reduction of the education gender gap due to the rebalancing across genders of education investment resulting from the diffusion of time-saving appliances, which shapes the demographic transition in developing countries.

Doepke (2004) shows (in a unified growth theory framework) that the introduction of child labor regulations accounts for the different timings and speeds of the demographic transition across countries. Hazan and Berdugo (2002) consider child labor too, and argue that during the development process, technological progress enlarges the wage differential between parental and child labor, thereby inducing

\footnotetext{
${ }^{5}$ Using US data at county level, Bailey and Collins (2011) have identified a negative coefficient of the home technology adoption rate on fertility, while a baby boom implies a positive one. This result is usually interpreted as evidence contradicting Greenwood et al. (2005b). But in a paper reply to these finding, Greenwood et al. (2015) point to a misinterpretation by Bailey and Collins (2011), who ignore that poorer households adopted electricity and home appliances later than richer ones, while the latter intrinsically have lower fertility rates.
} 
a substitution of child education for child labor, which in turn reduces fertility. In an open economy model, the authors suggest that a compulsory schooling policy and an intergenerational transfer to the elders would be Pareto-improving and would accelerate development. While not contradicting these papers, our approach is different in not focusing child labor. We pay instead particular attention to the effect of creating and diffusing home appliances on education investment in children and on fertility during the development process.

Regarding women's rights and evolution of human capital, Doepke and Tertilt (2009) argue that an expansion of wives' legal rights increases human capital investment for children. This, in turn, helps children to find quality spouses, just like fathers wish for their children. Thus, when voting on women's rights, men hold conflicting goals, between the diminished rights they want for their own wives and the expanded rights they wish for other women. Men's weight on these goals shifts over time with the increasing value of human capital as technological progress takes place, shaping the evolution of human capital and demographic transition.

The model by De la Croix and Vander Donckt (2010) is based on intra-household bargaining to analyse the impact of gender inequality on economic outcomes for least developed countries. It points to the increasing survival probabilities of females and infants, making women more likely to be active in the market and leading to an increase in female education as a key means to escape poverty. Furthermore, higher female education increases women's bargaining power within the household, decreasing fertility and improving the quality of children, and so fostering economic growth. ${ }^{6}$

Our paper could have followed the literature of women's empowerment and development more closely (Duflo 2012, Doepke and Tertilt 2019, Hazan et al. 2019). But we do not engage in this interesting debate here. In our view, this literature does not contradict, but rather complements, our paper. The interdependence between women's empowerment and development is a naturally complex issue that no single model captures, the exact nature of the link between women's empowerment and development remaining elusive.

Finally, as for the empirical literature on gender equality and development, most papers study the effects of gender inequality in education or human capital on economic growth: e.g. Barro and Lee (1994), Dollar and Gatti (1999), Klasen (2002), and Klasen and Lamanna (2009), among others. More recently, Klasing and Milionis (2020) show the empirical link between improvements in life expectancy and the closing of the education gap across genders - as the global spread of Western medicine against infectious diseases led to relatively larger gains in female life expectancy. These results complement ours to explain the improvement of gender equality in education in the 20th century, since the model can be extended to capture the effect of an increase in life expectancy on fertility and education investment, in order to explain the empirical evidence in Klasing and Milionis (2020). Regarding fertility, human capital and development, Vogl (2016) shows empirically that before 1960 children from larger families obtained more education because they had richer and more educated parents, while this pattern had reversed by the end of the 20th century. These results again also do not contradict ours, even if our model does not take into account heterogeneity across households.

${ }^{6}$ On women's rights and marital bargaining power see also Basu (2006), Fernandez (2009), Doepke et al. (2012), Doepke and Tertilt (2019). 


\section{The Model}

This section sets up a model to explain the demographic transition in developing countries. Accordingly, it does not take into account the markets for childcare services and housework aid that contributed to shape fertility patterns in developed countries throughout the second half of the 20th century. Instead, it focuses on the introduction and diffusion of home appliances and their impact on households' decisions on education investment, female labor force participation, and fertility. The economy consists, at any period $t$, of a number $L_{t}$ of identical 2-people and 2-gender (male and female) households. Each member of a household lives for two periods - childhood and adulthood - and is endowed with one unit of time when adult. Adults (i) allocate their time between supplying labor, doing housework, and childrearing, (ii) decide how much to invest in their children's human capital, and (iii) consume the remainder of their income. As in Becker (1985), in order to capture gender gaps in earnings and human capital, childrearing and housework are assumed to be carried out by the woman, in accordance with cross-cultural evidence. ${ }^{7}$ Regarding childrearing, each household's "child" —also a 2-people, 2-gender household - requires $\rho$ units of parents time, while the human capital of each member of a "child" household is a power $\theta \in(0,1)$ of the parent household's education investment, $e_{t}$ for a son and $\tilde{e}_{t}$ for a daughter. As for housework time, it is assumed to be decreasing with technological progress, so that the fraction of time $\phi_{t} \in[0,1)$ devoted by period $t$ 's adult household to housework is a function $\phi_{t}=\phi\left(a_{t}\right)$ of the technological level $a_{t}$ satisfying the following assumption ${ }^{8}$

Assumption 1. $\phi^{\prime}(a)<0$ and $\lim _{a \rightarrow+\infty} \phi(a)=0$.

For the sake of simplicity, we do not assume that childcare time $\rho$ decreases with technology. ${ }^{9}$ In the model, $\rho$ should be interpreted as the time for pregnancy, initial care, and breastfeeding being closely linked to the birth. As for the housework time $\phi(a)$, it could alternatively be made to depend on the size of the household. However, in developing countries children usually participate in housework alongside their parents (see Webbink et al. 2012) so that fertility has opposite effects on women's housework burden. For the sake of simplicity, we assume that these effects offset each other. Finally, we model housework as unavoidable and hence as not being a choice variable. That fits well into the case of developing countries in which the outsourcing of household chores is almost nil.

\subsection{Households}

Households choose consumption $c_{t}$, the number of their household-children $n_{t},{ }^{10}$ and the potential income of the latter through its education investment in human capital $e_{t}$ for sons and $\tilde{e}_{t}$ for daughters solving

\footnotetext{
${ }^{7}$ Specially in developing economies, conventions still make women responsible for childrearing and housework, while the labor market for mostly physically demanding tasks leads households to specialise in a division of labor that sees almost only men participating in wage labor. In Galor and Weil (1996), the opportunity cost of raising children is higher for men than women. Thus, the woman takes care of children until her time constraint is binding, when the man gets involved. However, Galor and Weil (1996) restrict the weight of children in preferences so that men do not participate in childrearing, devoting instead all their time to wage labor. Anyway, letting men do housework and childcare does not change the qualitative analysis as long as it is assumed they do less than women, which seems uncontroversial.

${ }^{8}$ Greenwood et al. (2005a) argue that technological progress plays a key role in households' allocation of time. Indeed, the appearance of a mass market for ready made clothes (in the 19th century) and the generalization of appliances —washing machines, vacuum cleaners, refrigerators (in the mid-20th century), etc. - as well as frozen foods and ready meals (in the mid-late 20th century) freed a considerable amount of time from housework.

${ }^{9}$ This effect, that would indeed foster fertility, can be introduced without changing the qualitative results, in particular, the explanation of the hump-shaped fertility pattern. On the increasing part of the hump, this effect reinforces our mechanism, while on the decreasing part it is dominated by the reduction in fertility through an increased gender equality in education — for reasonable parameters and functional forms.

${ }^{10}$ We assume that the gender birth ratio (male over female) is 1 which is close to the natural gender ratio. Accordingly, a "household-child" is assumed to consist of a son and a daughter.
} 


$$
\max _{c_{t}, n_{t}>0 ; e_{t}, \tilde{e}_{t} \geq 0}(1-\gamma) \ln c_{t}+\gamma \ln \left(n_{t} w_{t+1}\left[e_{t}^{\theta}+\left(1-\phi_{t+1}\right) \tilde{e}_{t}^{\theta}\right]\right)
$$

subject to

$$
\begin{gathered}
c_{t}+n_{t}\left(e_{t}+\tilde{e}_{t}\right) \leq w_{t}\left[e_{t-1}^{\theta}+\left(1-\phi_{t}-\rho n_{t}\right) \tilde{e}_{t-1}^{\theta}\right] \\
\phi_{t}+\rho n_{t} \leq 1
\end{gathered}
$$

given the wage rates $w_{t}, w_{t+1}$ and the time $\phi_{t}, \phi_{t+1}$ needed for housework, at $t$ and $t+1$, as well as the education investments $e_{t-1}$ and $\tilde{e}_{t-1}$ made by the household's parents. ${ }^{11}$ The parameter $\gamma \in(0,1)$ captures the household's degree of altruism.

A household adult at $t$ is thus assumed to perfectly foresee the fraction of time $\phi_{t+1}$ that its household-children will devote to housework, since this is determined by its own average human capital through technological progress. ${ }^{12}$ But the adult will not foresee what results follow from its children's choices, hence the absence of $\rho n_{t+1}$ in the objective. Thus, since households derive utility from their children's potential income $w_{t+1}\left[e_{t}^{\theta}+\left(1-\phi_{t+1}\right) \tilde{e}_{t}^{\theta}\right]$, parents always invest in their daughters' education regardless of the latter's choice on childrearing and housework time. ${ }^{13}$

It follows from the necessary first order conditions of the problem (derived in the Appendix) that, since by Assumption 1 housework time $\phi_{t}=\phi\left(a_{t}\right)$ decreases with the technological level $a_{t}$, the time constraint is not binding, so that women supply labor to the market, whenever $a_{t}$ is beyond

$$
a^{*}=\phi^{-1}\left(1-\left[\frac{\gamma(1-\theta)}{1-\gamma(1-\theta)}\right]^{1-\theta}\right)
$$

The following assumption guarantees that $a^{*}>0$.

Assumption 2. $\phi(0)=\bar{\phi}>1-\left[\frac{\gamma(1-\theta)}{1-\gamma(1-\theta)}\right]^{1-\theta}>\phi(a)$, for some $a>0 .^{14}$

Assumption 2 requires (for very low technologies) housework time to be so high as to keep women away from the labor market. Without this assumption, the time constraint would never be binding, women would always participate in the labor market regardless of the level of technology, and fertility would always be decreasing in the latter. Nevertheless, in the early stages of development, fertility is typically observed to increase with the level of technology, and women participate in the labor market only when the return to labor is high enough. Assumption 2 allows chosen fertility to be expressed as

$$
n_{t}= \begin{cases}\frac{1-\phi\left(a_{t}\right)}{\rho} & \text { if } \quad a_{t} \leq a^{*} \\ \frac{\gamma(1-\theta)}{\rho}\left[\left[1-\phi\left(a_{t}\right)\right]^{\frac{\theta}{\theta-1}}+1-\phi\left(a_{t}\right)\right] & \text { if } \quad a_{t} \geq a^{*}\end{cases}
$$

\footnotetext{
${ }^{11}$ The main results of our model do not change if we assume that the input for education investment is parents' time instead of income, while this alternative modelling choice requires additional assumptions about who - the father or the mother- is responsible for it, or what is the parents' division of labor in educating children. At any rate, regardless of this, the education investments in our model would correspond, in the alternative approach, to the opportunity cost of educating children. All in all, the gender gap in education and its properties are determined by equations (11) and (12) whose qualitative behaviour does not depend on this modelling choice. Ours is, at any rate, in accordance with the fact that the importance of formal education for the labor market increasingly exceeds that of education involving parents' time.

${ }^{12}$ Indeed, $\phi_{t+1}$ has been assumed to be determined by the level of technology $a_{t+1}$, which itself is determined by the education investments $e_{t}$ and $\tilde{e}_{t}$ chosen for this household by its parent household (see equation (13) below), all of which is known to it.

${ }^{13}$ That is to say, a daughter's education has a value for her parents, independently of the use that she makes of it. This is consistent with Becker and Tomes (1979) and Galor and Weil (2000), and captures other aspects excluded from the model, like the use of education as hedging device against the risk of a daughter's divorce: see Chiappori and Weiss (2007).

${ }^{14}$ This necessarily requires the condition $1-\left[\frac{\gamma(1-\theta)}{1-\gamma(1-\theta)}\right]^{1-\theta}>0$ - since $\phi$ is decreasing and non-negative for all $a-i . e . \gamma(1-\theta)<1 / 2$ must holds. This last condition obviously holds for an altruism factor $\gamma<1 / 2$, conventionally assumed in the literature: e.g. Galor and Weil (1996), Doepke (2004), and Lagerlöf $(2003,2006)$. We will restrict the value of $\theta$ in such a way that this condition holds.
} 
Comparative statics for education investments and fertility in (16), (17), and (18) with respect to the wage rate $w_{t}$ and parameters $\rho, \gamma$ deliver

$$
\begin{array}{rrr}
\frac{\partial e_{t}}{\partial w_{t}}, \frac{\partial \tilde{e}_{t}}{\partial w_{t}} ; \frac{\partial e_{t}}{\partial \rho}, \frac{\partial \tilde{e}_{t}}{\partial \rho}>0 & \text { and } & \frac{\partial n_{t}}{\partial w_{t}}=0, \frac{\partial n_{t}}{\partial \rho}<0 \\
\frac{\partial e_{t}}{\partial \gamma}, \frac{\partial \tilde{e}_{t}}{\partial \gamma}\left\{\begin{array}{llll}
>0 & \text { if } \phi_{t}+\rho n_{t}=1 \\
=0 & \text { if } \phi_{t}+\rho n_{t}<1
\end{array}\right. & \text { and } & \frac{\partial n_{t}}{\partial \gamma}\left\{\begin{array}{lll}
=0 & \text { if } & \phi_{t}+\rho n_{t}=1 \\
>0 & \text { if } & \phi_{t}+\rho n_{t}<1
\end{array}\right.
\end{array}
$$

Thus, when the woman's time constraint is not binding, a rise in the wage rate $w_{t}$ generates income and substitution effects on fertility such that the former raises fertility while the latter, which reflects an increase in the opportunity cost of childrearing, reduces it. From the homotheticity of preferences, the two effects offset each other. A rise in $w_{t}$ translates therefore into a rise in education investments for children. As for the impact of the time cost of childrearing, an increase in $\rho$ reduces the fertility of the household, that trades child quantity for child quality, increasing the education investments.

When women's time constraint is binding, a higher weight $\gamma$ for children in preferences makes parents invest more in their children's education. When the time constraint of the woman is not binding, a higher $\gamma$ increases fertility without changing education investments, as it generates two opposite effects on child quality. On the one hand, it makes parents allocate more resources to children, both for child quantity and quality. On the other hand, it increases the marginal costs of education investments through the increase in fertility $n_{t}$. The two effects cancel out, leaving education investments unchanged.

Finally, equations (16) and (17) show that when the woman's time constraint is not binding, children's education depends on the income of the mother only, since an increase in the father's income has two opposing effects on children's education that cancel each other out: the income effect increases the number of children, but the increase in the number of children increases the marginal cost of education investment for all children.

\subsection{Production}

Output $y_{t}$ is linear in the effective units of labor supplied, ${ }^{15}$ so that

$$
y_{t}=A_{t}\left[e_{t-1}^{\theta}+\left(1-\phi_{t}-\rho n_{t}\right) \tilde{e}_{t-1}^{\theta}\right]
$$

where $A_{t}>0$ is the productivity per effective unit of labor, and hence the return to human capital and the wage rate too (i.e. $\left.w_{t}=A_{t}\right)$. Productivity is assumed to be a function where $A_{t}=A\left(a_{t}\right)$ of the level of technology $a_{t}$, with $A(a)>0$ and $A^{\prime}(a)>0$ for all $a>0$, as well as $\lim _{a \rightarrow+\infty} A(a)=\bar{A}$. In turn,

\footnotetext{
${ }^{15}$ For the sake of simplicity, we do not take into account physical capital. However, the main results are robust when introducing physical capital and assuming diminishing returns for all production factors. Indeed, with physical capital and 3-period living households working and saving in the second period and consuming in the third - the first period being childhood - savings are lent to firms and their return is consumed in the third period, while education investments and fertility choices remain the same. Also, we ignore consumption when young. Nonetheless, with a log-linear utility the saving rate is constant and fertility is independent of the interest rate, and consumption when young could be incorporated into the logarithm utility function, altering the dynamics of the model by just a multiplicative constant.
} 
technology is assumed to evolve according to

$$
a_{t+1}=\left[1+g\left(\frac{e_{t-1}^{\theta}+\tilde{e}_{t-1}^{\theta}}{2}\right)\right] a_{t}
$$

where the rate of technological progress between $t$ and $t+1$ is determined by the average human capital - as a function of education investments - of the generation educated at $t-1$ and working at $t$, with $g(\cdot)>0, g^{\prime}(\cdot)>0 .{ }^{16}$ We consider the impact of average (rather than aggregate) human capital on technological progress, not taking into account the population size. For the impact of population size on technological progress see for example Galor and Weil (2000), Galor (2005), and Dao and Dávila (2013), according to whom population growth fostered technological progress in the very early stages of development, before education takes place. Beyond some technological level, education plays the essential role and the marginal effect of population size on technological progress is negligible. In the 20th century, population in the developing world was already big and the level of technological high, while education investment was growing. For the sake of simplicity, we ignore the impact of population size on technological progress, without loss of generality for the qualitative results of the model.

\subsection{Equilibria}

At equilibrium, households maximize their utility according to their budget constraints, while output matches consumption and education investment, in every period $t$, given the dynamics for technology. A competitive equilibrium is thus characterized - given initial conditions $e_{-1}, \tilde{e}_{-1}, a_{0}-$ by a reduced dynamics in the education investments for sons and daughters $e_{t}$ and $\tilde{e}_{t}$, along with the level of technology $a_{t+1}$,

$$
\begin{aligned}
& e_{t}=\left\{\begin{array}{lll}
\frac{\gamma \theta}{1-\gamma+\gamma \theta} \frac{\rho}{\left(1-\phi\left(a_{t}\right)\right)\left(1+\left[1-\phi\left(a_{t+1}\right)\right]^{\frac{1}{1-\theta}}\right)} A\left(a_{t}\right) e_{t-1}^{\theta} & \text { if } & a_{t} \leq a^{*} \\
\frac{\theta}{1-\theta} \frac{\rho}{1+\left[1-\phi\left(a_{t+1}\right)\right]^{\frac{1}{1-\theta}}} A\left(a_{t}\right) \tilde{e}_{t-1}^{\theta} & \text { if } & a_{t} \geq a^{*}
\end{array}\right. \\
& \tilde{e}_{t}=\left\{\begin{array}{lll}
\frac{\gamma \theta}{1-\gamma+\gamma \theta} \frac{\rho}{\left(1-\phi\left(a_{t}\right)\right)\left(1+\left[1-\phi\left(a_{t+1}\right)\right]^{\frac{1}{\theta-1}}\right)} A\left(a_{t}\right) e_{t-1}^{\theta} & \text { if } & a_{t} \leq a^{*} \\
\frac{\theta}{1-\theta} \frac{\rho}{1+\left[1-\phi\left(a_{t+1}\right)\right]^{\frac{1}{\theta-1}}} A\left(a_{t}\right) \tilde{e}_{t-1}^{\theta} & \text { if } & a_{t} \geq a^{*}
\end{array}\right. \\
& a_{t+1}=\left[1+g\left(\frac{e_{t-1}^{\theta}+\tilde{e}_{t-1}^{\theta}}{2}\right)\right] a_{t}
\end{aligned}
$$

given $e_{-1}, \tilde{e}_{-1}, a_{0}>0$.

\footnotetext{
${ }^{16}$ The impact of human capital on technological progress might depend on the effective participation of workers in production, so that $g$ would depend on $\frac{1}{2}\left(e_{t-1}^{\theta}+\left[1-\phi\left(a_{t}\right)-\rho n_{t}\right] \tilde{e}_{t-1}^{\theta}\right)$ instead. This would only slow down the transition to sustained growth, but not change it qualitatively (the proof is available upon request). It can nonetheless be argued that women's human capital impacts technological progress through childrearing via the children's cognitive abilities, capacity of adaptation to new knowledge, and health, which in turn impact their human capital. The function $g($.) describing the dynamics for technology follows the literature of unified growth theory, e.g. Galor and Weil (2000), Galor and Moav (2002), Diebolt and Perrin (2013 a, b).
} 


\section{The Evolution of the Economy towards its Long Run Regime}

Subsections 4.1 and 4.2 study the dynamics for gender inequality in education, fertility, female labor supply as they interact with technology. Subsection 4.3 addresses the convergence to sustained growth.

\subsection{Gender inequality in education}

Gender inequality in education is gauged by the female-to-male education investment ratio

$$
\mu_{t}=\frac{\tilde{e}_{t-1}}{e_{t-1}}
$$

That is to say, from (8) and (9), lagged one period, it follows that

$$
\mu_{t}=\frac{1+\left[1-\phi\left(a_{t}\right)\right]^{\frac{1}{1-\theta}}}{1+\left[1-\phi\left(a_{t}\right)\right]^{\frac{1}{\theta-1}}}=\left[1-\phi\left(a_{t}\right)\right]^{\frac{1}{1-\theta}} \equiv \mu\left(a_{t}\right)<1 \quad \text { with } \quad \mu^{\prime}\left(a_{t}\right)=\frac{\left[1-\phi\left(a_{t}\right)\right]^{\frac{\theta}{1-\theta}} \phi^{\prime}\left(a_{t}\right)}{\theta-1}>0
$$

so that: (i) there is an education bias against women when $\mu_{t}<1$; (ii) a higher $\mu_{t}$ means more equality across genders in education, with complete equality at $\mu_{t}=1$; and (iii) gender equality in education improves with technological progress. And, under Assumption 1 and given the technology dynamics in (10), the education gender gap eventually vanishes, i.e. $\lim _{a_{t} \rightarrow+\infty} \mu\left(a_{t}\right)=1$.

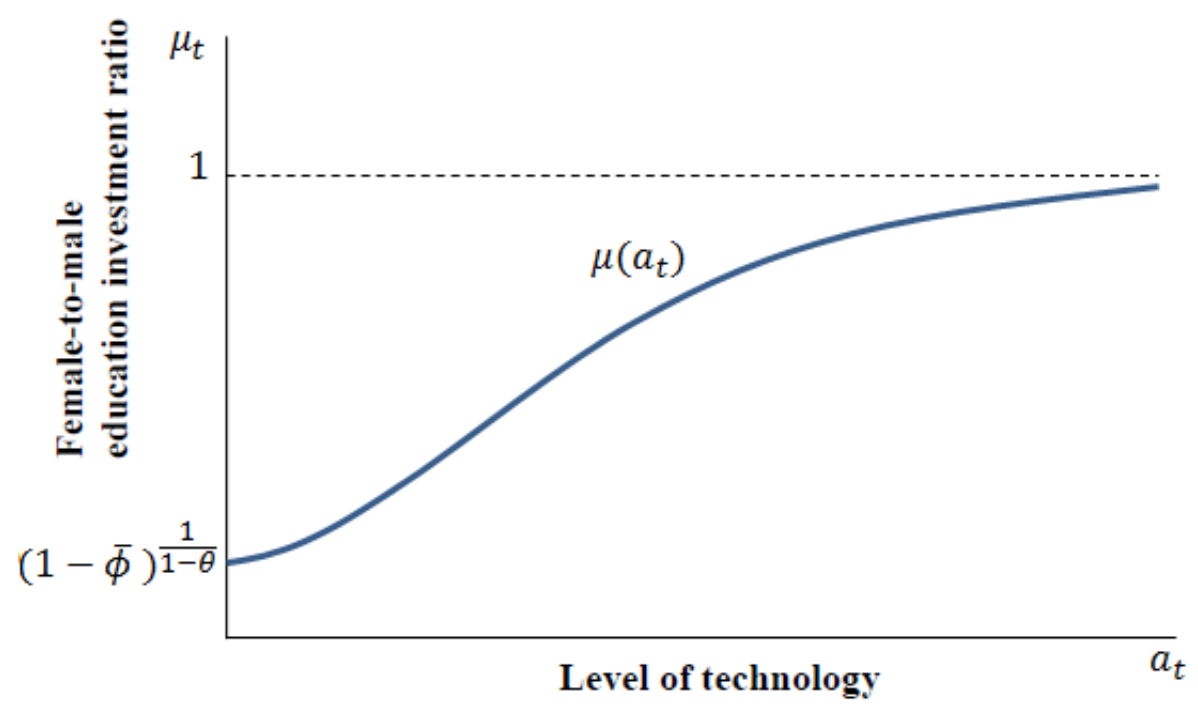

Figure 4: Gender inequality in education against level of technology.

Thus, parents' education choice is biased against daughters (i.e. sons receive more education investment than daughters) because women allocate a time to childrearing and housework for which they do not earn any income. ${ }^{17}$ Moreover, gender equality in education increases with the level of technology since a higher level of technology reduces housework time, so that women can increase their labor market participation, leading parents to invest more in their daughters' education in order to increase their labor productivity. As a result, inequality in education decreases with technological progress.

\footnotetext{
${ }^{17}$ In section 5 and in the Appendix we introduce heterogeneity across genders in non-cognitive skills to generate a reversal of this bias in education investment.
} 
In turn, the narrowing of the education gender gap speeds up technological progress, in a reinforcing feedback loop, as established in Lemma 1 next.

Lemma 1. Whenever the rate of technological progress increases with the average human capital, a better equality in education across genders (i.e. a higher $\mu_{t}<1$ ) implies a faster technological progress (i.e. a higher growth rate $g_{t}$ for $\left.a_{t}\right)$, for any given level of aggregate human capital

$$
e_{t}+\tilde{e}_{t}=\left\{\begin{array}{lll}
\frac{\gamma \theta}{1-\gamma+\gamma \theta} \frac{\rho}{1-\phi\left(a_{t}\right)} A\left(a_{t}\right) e_{t-1}^{\theta} & \text { if } & \rho n_{t}+\phi\left(a_{t}\right)=1 \\
\frac{\theta}{1-\theta} \rho A\left(a_{t}\right) \tilde{e}_{t-1}^{\theta} & \text { if } & \rho n_{t}+\phi\left(a_{t}\right)<1
\end{array}\right.
$$

- according to (8) and (9).

Proof. See Appendix A1.

Intuitively, Lemma 1 follows from the diminishing returns to education investment captured by $\theta \in(0,1)$, since a reallocation of education investments towards gender equality in education increases average human capital, and hence the rate of technological progress that boosts income growth. ${ }^{18}$

\subsection{Fertility and female labor supply}

To see how technology impacts fertility and female labor supply, we rewrite the fertility function

$$
n_{t}=n\left(a_{t}\right) \equiv \begin{cases}\frac{1}{\rho}\left[1-\phi\left(a_{t}\right)\right] \equiv n_{1}\left(a_{t}\right) & \text { if } \quad a_{t} \leq a^{*} \\ \frac{\gamma(1-\theta)}{\rho}\left[\left[1-\phi\left(a_{t}\right)\right]^{\frac{\theta}{\theta-1}}+1-\phi\left(a_{t}\right)\right] \equiv n_{2}\left(a_{t}\right) & \text { if } \quad a_{t} \geq a^{*}\end{cases}
$$

and define the women's fraction of time allocated to labor market participation as follows

$$
\mathcal{L}\left(a_{t}\right)=1-\rho n\left(a_{t}\right)-\phi\left(a_{t}\right)
$$

The following proposition states the responses of fertility and female labor force participation to a change in the level of technology.

Proposition 1. In the economy as set out above:

(i) When the level of technology is sufficiently low, in particular $a<a^{*}$, then

(i.a) fertility increases in technological level,

(i.b) women spend their full time rearing children and doing housework.

(ii) When the level of technology surpasses the threshold $a^{*}$ and the return on education does not decrease too quickly, in particular $\theta \in\left[\frac{1}{2}, 1\right),{ }^{19}$ then

(ii.a) fertility decreases with the level of technology, and converges to a constant level,

(ii.b) female labor force participation increases with the level of technology, and converges to an upper bound.

\footnotetext{
${ }^{18}$ Lemma 1 is also consistent with the empirical results in Klasen (2002) showing a positive effect of gender equality in education on economic growth. Klasen (2002) shows that gender inequality in education affects economic growth directly by lowering the average level of human capital, and indirectly through its impact on population and investment.

${ }^{19}$ This is just a sufficient condition to guarantee fertility decreasing with technological progress when the level of technology is high enough.
} 
Proof. Indeed,

$$
n_{1}^{\prime}\left(a_{t}\right)=-\frac{1}{\rho} \phi^{\prime}\left(a_{t}\right)>0 \quad \text { and } \quad n_{2}^{\prime}\left(a_{t}\right)=\frac{\gamma(1-\theta)}{\rho}\left[\frac{\theta}{1-\theta}\left[1-\phi\left(a_{t}\right)\right]^{\frac{1}{\theta-1}}-1\right] \phi^{\prime}\left(a_{t}\right)<0
$$

Note that $n_{1}\left(a_{t}\right)$ starts below $n_{2}\left(a_{t}\right)$ at the origin, since

$$
n_{1}(0)=\frac{1-\bar{\phi}}{\rho}<\frac{\gamma(1-\theta)}{\rho}\left[(1-\bar{\phi})^{\frac{\theta}{\theta-1}}+1-\bar{\phi}\right]=n_{2}(0)
$$

while $n_{1}\left(a_{t}\right)$ converges to a higher limit than $n_{2}\left(a_{t}\right)$, overtaking $n_{2}\left(a_{t}\right)$ at $a^{*}$, as $a_{t}$ increases

$$
\lim _{a_{t} \rightarrow+\infty} n_{2}\left(a_{t}\right)=\frac{2 \gamma(1-\theta)}{\rho}<\frac{1}{\rho}=\lim _{a_{t} \rightarrow+\infty} n_{1}\left(a_{t}\right)
$$

And

$$
\begin{aligned}
& \mathcal{L}\left(a_{t}\right)=\left\{\begin{array}{ccc}
0 & \text { if } & a_{t} \leq a^{*} \\
1-\rho n_{2}\left(a_{t}\right)-\phi\left(a_{t}\right) & \text { if } & a_{t} \geq a^{*}
\end{array}\right. \\
& \mathcal{L}^{\prime}\left(a_{t}\right)=\left\{\begin{array}{ccc}
0 & \text { if } & a_{t}<a^{*} \\
-\rho n_{2}^{\prime}\left(a_{t}\right)-\phi^{\prime}\left(a_{t}\right)>0 & \text { if } & a_{t}>a^{*}
\end{array} \quad \text { and } \quad \lim _{a_{t} \rightarrow+\infty} \mathcal{L}\left(a_{t}\right)=1-2 \gamma(1-\theta) .\right.
\end{aligned}
$$

The effects of technological progress on fertility and female labor force participation are illustrated in Figure 5.

Thus, while at low enough levels of technology women's time is entirely devoted to childrearing and housework, as $a_{t}$ increases (but stays below $a^{*}$ ) the time freed from housework shifts to childrearing so that, during the early stages of development, technological progress increases fertility. ${ }^{20}$ As $a_{t}$ surpasses $a^{*}$, women enter the labor market and carry out housework, childrearing only part-time. Technological progress shrinks the human capital gender gap in (12) because of the higher return to female education and the additional time for female labor market participation. In turn, the higher female labor market participation and the decrease in the education gender gap reduce the earnings gender gap also. The increase in women's earnings raises, in turn, the opportunity cost of childrearing. Thus, as the cost of raising children increases, households substitute the quality of children to quantity. ${ }^{21}$

\footnotetext{
${ }^{20}$ Some studies in the literature provide empirical evidence on the positive correlation between income/productivity and fertility in early stages of development supporting this Malthusian feature (see Crafts and Mills (2009) for England in the 16th-18th centuries, Lagerlöf (2015) for Sweden in the 18th-19th centuries, and Ashraf and Galor (2011) for the period 1-1500 CE). Several theories also predict such a positive correlation in early stages of development (see e.g. Malthus 1798, Galor and Weil 2000, Galor and Moav 2002).

${ }^{21}$ The model abstracts from child mortality to explain the demographic transition. Indeed, there has been a lack of consensus in the literature about the role of child mortality in explaining demographic transition. Kalemli-Ozcan (2002, 2003), Tamura (2006), Tamura et al. (2016), Tamura and Simon (2017), and recently Cuberes and Tamura (2019) are in favor of the view that falls in child mortality may induce declines in fertility. Using the altruistic parents model of Barro and Becker (1989), Doepke (2005) provides results suggesting that the fall in net fertility during the 19th century in the industrialized countries was driven by factors other than the fall in child mortality, pointing out that the decline in child mortality has been dismissed as a cause of the decline in fertility, because of the inconsistency of this link. Galor (2012) shares this view, showing that the fall in fertility in Western Europe started nearly a century after the decline in child mortality. Herzer et al. (2012) show a positive correlation between child mortality and fertility in the 20th century, but not a strong enough relationship to explain the secular decline of population growth. Murphy (2015) has shown empirically that child mortality had no impact on fertility during the demographic transition in France, while female education seems to have played a role. Recently, Blanc (2019) provides an interesting discussion on the determinants of the demographic transition in France.
} 


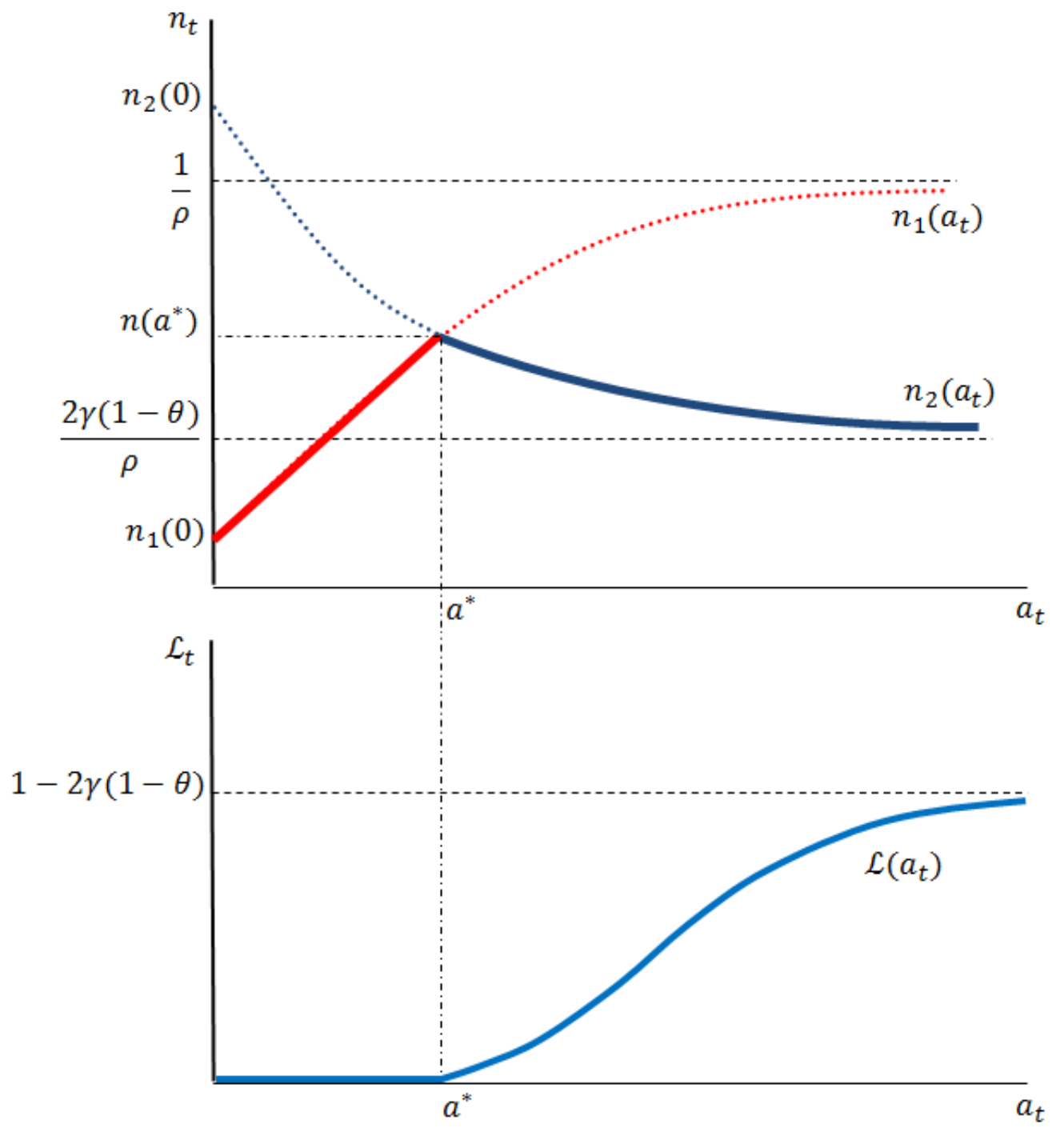

Figure 5: Fertility (upper graph) and female labor-force participation (lower graph) against technology

Finally, note that while the model predicts a female labor supply which is constant at zero when fertility is increasing, this is consistent with the reports in Goldin (1995) of a sharp increase in female clerical employment in the US during period 1890-1950, as the reported labor supply increase is associated with a decline in fertility during that period, i.e. when the technological level exceeded threshold $a^{*}$.

\subsection{Long run convergence}

The long run behavior of the economy in Section 3 is characterized in the following proposition.

Proposition 2. The overlapping generations economy converges -from any initial conditions $a_{0}, e_{-1}$, $\tilde{e}_{-1}>0$ - to a stationary regime of sustained growth characterized by:

(i) a growth rate of technology $\bar{g}$,

(ii) high education investments $\bar{e}$ and complete equality across genders,

(iii) a low fertility rate $\bar{n}$.

Proof. Firstly, Proposition 2 hinges next on the following Lemma 2 whose proof is in Appendix A2. 
Lemma 2. For $x_{t+1}=m_{t} x_{t}^{\alpha}$ with $0<\alpha<1, x_{0}>0$, and $\lim _{t \rightarrow+\infty} m_{t}=m>0$, it holds $\lim _{t \rightarrow+\infty} x_{t}=m^{\frac{1}{1-\alpha}}$.

Thus, according to (10), since $e_{t}>0$ or $\tilde{e}_{t}>0$ for all $t$, the level of technology $a_{t}$ increases unboundedly over time. Therefore, since $\lim _{a \rightarrow+\infty} \phi(a)=0$ is decreasing and $\lim _{a \rightarrow+\infty} A(a)=\bar{A}$ is increasing, it follows from (8), (9) and Lemma 2 that technology will progress asymptotically at a constant rate

$$
\bar{g}=g\left(\bar{e}^{\theta}\right) \quad \text { where } \quad \bar{e}=\lim _{t \rightarrow+\infty} \tilde{e}_{t}=\lim _{t \rightarrow+\infty} e_{t}=\left[\frac{\theta}{1-\theta} \frac{\rho}{2} \bar{A}\right]^{\frac{1}{1-\theta}}
$$

Finally, from (14), the fertility will converge at a decreasing rate towards the constant rate

$$
\bar{n}=\lim _{t \rightarrow+\infty} n_{2}\left(a_{t}\right)=2 \frac{\gamma(1-\theta)}{\rho}
$$

Proposition 2 is consistent with the modern regime of sustained growth characterized by unbounded economic growth, a low and decreasing fertility rate, and high human capital. It allows the process experienced by developing countries in the 20th century to be accounted for, and which was characterized by: (i) an initial increase in per capita income and fertility; (ii) a demographic transition after which fertility fell while per capita income kept growing; and (iii) a final regime of sustained growth with fertility converging to a low level and accelerated per capita income growth. During the transition through these three stages, gender equality in education and income, as well as female labor force participation, increased steadily.

Indeed, consider an economy at an early stage of development, with a low level of technology $a_{0}<a^{*}$ and low human capital across genders. The low technological level prevents women from participating in the labor market in two ways. First, directly, as a large fraction of women's time is required for housework. Second, indirectly, as the low level of technology biases the education investments against daughters, ${ }^{22}$ making the opportunity cost of childrearing too low, so that households choose a high fertility rather than female labor market participation. In turn, as at this early stage, household income is very low — due to the low human capital and low technological level — households' education investments are very small too. Average human capital, which drives technological progress, is very low for both male and female children, and the growth rate of technology therefore also remains low. In addition, at this early stage of development, since housework requires a very large fraction of women's time, the remaining time for childrearing is very small, so that the population growth rate is initially low. Nevertheless, since technology improves even when the average human capital is small, albeit very slowly, the technological level eventually increases, so that housework time decreases, as long as it stays low enough (i.e. for $a_{t}<a^{*}$ ). This frees time for childrearing, while the cost of childrearing is still low, so that the fertility rate increases. As the technological level $a_{t}$ increases, fertility increases and reaches a maximum when $a_{t}$ reaches $a^{*}$. When it increases even further (i.e. for $a_{t}>a^{*}$ ), women start and increase their labor market participation due to two effects. First, technological progress reduces housework time. Second, it improves the return to human capital, increasing women's earnings, and

\footnotetext{
${ }^{22}$ Households anticipate the large fraction of time that daughters will have to devote to housework, due to the low level of technology. Since men's supply of labor to the market is inelastic, while women have to spend a fraction of their time for housework, households allocate most of their education investment to their sons, making the education of their offspring very unequal across genders.
} 
thus raising the opportunity cost of childrearing. Fertility therefore decreases as the level of technology increases. It follows also from (8) and (9) that the total education investment increases with the level of technology when $a_{t}>a^{*}$, so that households substitute quality to quantity in their fertility choice. The increase in the level of technology makes households invest relatively more in daughters' education as the return to female education is higher and, as a consequence, gender equality in education improves, accelerating technological progress. This reinforcing feedback loop makes the economy enter a regime of sustained economic growth.

\section{Discussion}

Our model captures key aspects of the development process experienced by many developing countries during the late 20th end early 21st centuries, but it does not address them all. Related to this process there is, for instance, the U-shaped relation between female labor force participation and income, the U-shaped relation between women's education and fertility, and the reversal in education across genders that we discuss next. Other aspects not captured by the model like the link between women's empowerment and development (Duflo 2012, Doepke and Tertilt 2019, and Hazan et al. 2019, among others) are worth integrating into future research.

As for the U-shaped relationship between female labor force participation and income, the model predicts that female labor force participation never decreases with the level of technology, and increases when the latter is high enough, specifically for $a_{t}>a^{*}$, which is consistent with Galor and Weil (1996). Nevertheless, Goldin (1995) and Mammen and Paxson (2000) find an empirical U-shaped relation between female labor force participation and per capita income, across countries and stages of economic development. Goldin (1995) argues that, during early stages of development, most households live in rural areas where childrearing and agricultural work are easily compatible, and women are often unpaid workers on their family farms. As incomes increase, driven by technological progress going hand in hand with urbanization, female labor force participation rates fall because of an income effect and a fall in the demand for female labor in agriculture.

Our model is actually silent about women's non-market activities during the early stages of development, considering only formal labor market participation. Galor and Weil (1996) discuss variations of their model that generate a U-shaped relationship. One of them consists of considering that women can produce marketable goods at home, as well as taking care of childrearing, which can be incorporated in the current model to replicate the U-shaped relationship in Goldin (1995). Indeed, if we assume that home production is compatible with childrearing and housework, and the time for home production $\tilde{\phi}\left(a_{t}\right)$ is a decreasing function of the level of technology so that women spend a large fraction of time doing housework and home production during the early stages of development when the level of technology is low, then the low fertility rate in this period is combined with a high rate of female participation in the labor force. As the level of technology increases - reducing housework time and home production time - fertility increases. When technology reaches a high enough level, increasing the return to female education, women enter the paid labor force, generating a persistent increase in female labor market participation rates. 
Looking at the current U-shaped relationship between women's education and fertility in the US, Hazan and Zoabi (2015a) recently used the emergence of markets for childcare and housework aid to explain the current U-shaped relationship between women's education and fertility in the US. Nonetheless, while these factors matter for developed countries, where increases in female education and labor force participation go hand in hand with outsourcing housework and childrearing to cheap immigrant labor and kindergartens, these factors play much less of a role in developing countries. Thus, Hazan and Zoabi (2015a) do not contradict the stylized fact of a negative correlation between fertility and the female-to-male education ratio addressed in this paper.

As for the reversal in education across genders, Goldin et al. (2006) show that by 2002 women's college enrollment rates exceeded men's in 15 out of 17 OECD countries, compared to 4 out of 17 in the mid-1980s. Interestingly, the reversal in education across genders has not only taken place in developed countries but also in many developing ones (Becker et al. 2010). This phenomenon has generated a lot of research recently, and several factors, causes, and mechanisms have been proposed to explain it. ${ }^{23}$ In the Appendix, we present a modification of our model incorporating a difference in non-cognitive skills across genders to generate a reversal in the education gap within our mechanism. The difference in non-cognitive skills may refer to, for example, the degree of self-motivation and seriousness in study, the dislike of homework exercises, and the like. A poorly non-cognitively skilled person finds school more difficult and hence more costly (Becker et al. 2010). The effects of heterogeneity in non-cognitive skills on college costs across genders in Goldin et al. (2006) and Becker et al. (2010) can be reinterpreted as the fact that investing in education for an average daughter is more efficient than that for an average son.

\section{Empirical Analysis}

In this section, we illustrate the correlation which has existed within developing countries during the second half of the 20th century and the early 21st century between technical progress on the one hand and fertility, woman's education and woman's employment on the other hand. Our theoretical model suggests that the impact of technological progress on fertility, the gender gap in education and female formal labor force participation is transmitted through the creation and diffusion of labor-saving home appliances. More specifically, our model-based hypotheses can be stated, in the context of developing countries throughout the 20 th century, as follows:

- H1: Fertility has an inverted U-shaped response to the increasing creation and diffusion of laborsaving home appliances.

- H2: The increasing creation and diffusion of labor-saving home appliances reduces the gender gap in education investment.

\footnotetext{
${ }^{23}$ An incomplete list includes, to name but a few: the cost of college education (Goldin et al. 2006 and Becker et al. 2010), the rise of divorce rates (Goldin et al. 2006 and Chiappori et al. 2009), discrimination in labor market (Gosling 2003, Chiappori et al. 2009, Hazan and Zoabi 2015b), technological progress in the household sector (Chiappori et al. 2009), a short supply of men in the marriage market (Iyigun and Walsh 2007), differences in the anticipated dispersion of future wages across genders (Charles and Louh 2003), and the independence of fertility on the gender composition of the children when the return to human capital is sufficiently high (Hazan and Zoabi 2015b).
} 
- H3: The increasing creation and diffusion of labor-saving home appliances increases the female formal labor-force participation.

A challenge for the empirical investigation is the unavailability of data about the diffusion and uses of labor-saving home appliances in the household sector for emerging and developing countries. Hitherto existing empirical studies on the impact of home appliances on gender-related issues such as fertility and economic participation are mostly based on developed countries. Cavalcanti and Tavares (2008), for example, show by using data for OECD countries between 1980 and 1999, that declining prices and the greater availability of home appliances have a positive impact on female labor force participation. To control for endogeneity, they use the manufactured price index and the terms of trade adjustment as instrumental variables for the price index of home appliances. However, as data on the price and diffusion of home appliances is not available for a large number of less-developed countries and time periods, we have to find plausible proxies.

In order to proxy the diffusion of labor-saving home appliances in less-developed countries, we use three different measures:

1. The density of telephone subscriptions (measure available for 149 emerging and developing countries; yearly observations for the time period 1960 to 2015; $N=5846$; data source: World Bank World Development Indicators)

2. The percentage of the population with access to electricity (measure available for 150 emerging and developing countries; yearly observations for the time period 1990 to 2014; $N=3652$; data source: World Bank World Development Indicators)

3. The percentage of households with a refrigerator (measure available for 67 emerging and developing countries; highly unbalanced panel covering the time period 1990-2015; $N=276$; data source: Demographic Health Surveys)

We investigate the within-country variations between fertility and the diffusion of technology by modeling Total Fertility Rates (TFRs) as a function of every single one of these three variables which proxy the diffusion of time-saving home appliances.

Our empirical setup is as follows: We first start with a simple model estimating TFRs as a function of the technology proxy, its squared term and country-fixed effects.

$$
T F R_{i, t}=\alpha+\alpha_{i}+\beta_{1} \log (\text { technology proxy })+\beta_{2} \log ^{2}(\text { technology proxy })+\varepsilon_{i, t}
$$

where $T F R_{i, t}$ is the total fertility rate of country $i$ in period $t$; and $\alpha_{i}$ is a dummy variable for country $i$.

We use the log of our technology variables in order to capture proportional rather than linear changes. Country-fixed effects are included in the regression analysis in order to implicitly control for country-specific variables that are constant over time. With this simple setup, we estimate thus the overall within-country variation between fertility and our technology proxies, which is tested for concavity. We then illustrate the estimated general within-country correlation pattern by plotting our real observations against the within-country variation that we have estimated by this simple model. 
In a second step, we add time-fixed effects and a series of control variables in order to test the robustness of the estimated within-country correlation:

$$
T F R_{i, t}=\alpha+\alpha_{t}+\alpha_{i}+\beta_{1} \log (\text { technology proxy })+\beta_{2} \log ^{2}(\text { technology proxy })+\sum_{j} \gamma_{j} c_{i, t}^{j}+\varepsilon_{i, t}
$$

where $\alpha_{t}$ is a dummy variable for year, $c_{i, t}^{j}$ s are country- and year-specific control variables.

Year-fixed effects capture the influence of aggregate time trends. Our control variables filter out technical advancement from other forms of progress, in economic, social, and institutional terms. This helps us interpret our technology variables as proxies of technical progress in the field of home appliances. The control variables are the log of GDP per capita and its square, population density, exports in $\%$ of GDP and the under-five mortality rate. They are taken from the World Bank World Development Indicators.

All regressions are run with cluster robust standard errors (cluster at country level). The estimation results with the standard errors are reported in Tables 1 and 2.

When using telephone lines and electricity as proxies for time-saving home appliances, we focus on developing and emerging countries by dropping advanced countries, tax heaven, very small countries with a population size smaller than 30,000, and oil exporting Arab countries from the World Bank's data base. ${ }^{24}$ The DHS data on the diffusion of refrigerators is available for emerging and developing countries only.

Access to electricity and the diffusion of refrigerators are certainly more plausible proxies for the diffusion of time-saving home appliances than the density of telephone subscriptions. But these measures contain important technical limitations for our empirical investigation: the observations are only available for a relatively short time period (from 1990 on), they cover a lower number of countries and are, in the case of refrigerator diffusion, very unevenly distributed over time (data on refrigerator diffusion is not available on a yearly basis in the DHS but is only observed every three to six years depending on the country). When using the density of telephone subscriptions, we dispose of almost 6,000 observations, while the number of observations is reduced by $40 \%$ when using access to electricity, and reduced to $5 \%$ only when using refrigerator diffusion.

In the following, regression results and illustrations of the within-country correlation patterns between fertility and technology are presented for all three technology proxies. However, due to the technical superiority of the first proxy in terms of country and time coverage, our further empirical investigations presented in this article focus on telephone density as proxy for time-saving home appli-

\footnotetext{
${ }^{24}$ List of dropped countries:

Advanced countries (GDP per capita in PPP higher than $\mathbf{3 0 . 0 0 0}$ USD in 2017): Australia, Austria, Belgium, Canada, Czech Republic, Finland, Denmark, Estonia, France, Germany, Iceland, Israel, Ireland, Italy, Japan, Lithuania, Luxembourg, Netherlands, New Zealand, Norway, Portugal, Slovakia, Slovenia, South Korea, Spain, Sweden, Switzerland, UK, USA;

Fiscal paradises, oil exporting Arab countries, and very small countries: American Samoa, Andorra, Aruba, Bahamas, Bahrain, Bermuda, British Virgin Islands, Brunei Darussalam, Channel Islands, Cayman Islands, Cyprus, Faroe Islands, Gibraltar, Guam, Greenland, Hong Kong, Isle of Man, Kuwait, Liechtenstein, Macao, Malta, Marshall Islands, Monaco, Nauru, Northern Mariana Islands, Oman, Palau, Panama, Qatar, San Marino, Saudi Arabia, Singapore, St. Martin (French part), Trinidad and Tobago, Turks and Caicos Islands, Tuvalu, United Arab Emirates, Virgin Islands (U.S.).

We also run alternative specifications which: (1) focus only on countries and time periods for which GDP per capita is smaller than 20,000 (constant 2010 USD); (2) exclude only the advanced countries listed in footnote 24; and (3) exclude only the fiscal paradises, oil exporting Arab countries and very small listed in footnote 24 . The results are consistent with those presented in this section. Results are available on request.
} 
ances. This concerns the empirical investigation of the within-country correlation between technology diffusion on the one side and the gender gap in education and female formal employment on the other side. We abstain from estimating correlation patterns between the other two technology proxies and the gender gap in education, respectively female formal employment, as these combinations of variables lead to fragmented and highly unbalanced data: data on female formal employment is only available from 1990 on and only for a subset of emerging and developing countries, and data on the gender gap in education is only available on a quinquennial basis.

Data on female formal labor-force participation comes from the World Bank World Development Indicators, covering the time period 1990 - 2015 (yearly observations). Data on education comes from the Barro and Lee Database, and observations are available from 1950 on, on a five-year basis (Barro and Lee, 2013). A summary of the panel data used for our empirical investigations can be found in Appendix A4. This appendix also provides a correlation matrix of all regressors used in our empirical analysis.

Telephone subscriptions certainly do not directly reflect the diffusion of labor-saving home appliances. However, as several studies have shown that the appearance of fixed telephone lines in households was observed soon after the arrival of other home appliances in the 20th century, even in the developing world, we assume that the penetration of telephone lines can be used as a plausible proxy for the diffusion of labor-saving home appliances. Studies by Paroush (1965), McFall (1969), Hebden and Pickering (1974), Kasulis et al. (1979), Dicken et al. (1983) or more recently Dholakia and Banerjee (2012), for example, order consumer acquisition priorities for home appliances during the second half of the 20th century. They show an absence of telephone lines in the priority list of home appliances while other time-saving appliances such as refrigerators, clothes washers, kitchens, ovens, etc. were listed. Dholakia and Banerjee (2012) point out the late penetration of telephone lines for the case of India. Such a pattern of acquisition priorities for home appliances is also observed in other developed countries at earlier time periods. Bowden and Offer (1994) point out the ranking of diffusion rate of selected home appliances in the US and Britain since 1920s, in which the penetration of telephone lines is ranked after those of refrigerators, electric irons, clothes washers, and vacuum cleaners. This time delay suggests that the observed penetration of telephone lines in households in the 20th century reflects the diffusion of many other time-saving home appliances a couple of years before. Furthermore, the evolution of telephone densities is found to be relatively homogenous across developing and emerging countries, while other proxies of technical advancements such as electricity consumption or air transport vary markedly even at similar income levels (World Bank 2008). This is also the case for internet diffusion, for which Andres et al. (2010) find a significant disparity within the group of emerging and developing countries. In addition, data on internet diffusion is only available from the 1990s on, and in most emerging and developing countries, internet has only been spreading since the early 2000s. Besides, the fact that in many developing countries, internet access develops independently of the infrastructure that is necessary to use household appliances, has led us to abstain from using internet diffusion as a proxy for time-saving home appliances.

For our empirical illustrations using telephone density as proxy for time-saving home appliances, we group together fixed and mobile telephone lines. We furthermore use the variable "number of fixed and 
mobile telephone lines per 100 inhabitants" with a 10-year forward gap as exogenous variable. This means, telephone density is observed 10 years later than fertility, which is due to the above mentioned priority order of owning home appliances. In concrete terms, in order to proxy the correlation of TFRs and labor-saving home appliances at time $t$, we use TFRs at time $t$ as endogenous variable and the density of telephone lines at time $t+10$ as exogenous variable. The density of telephone lines at time $t+10$ is supposed to reflect the access to labor-saving home appliances 10 years earlier, at the time when fertility outcomes are observed. ${ }^{25}$

\subsection{The effect of home appliances on fertility}

The first two columns of Table 1 present regression results of TFRs estimated as a function of the tenyear forward gap of $\log$ (telephone lines) and its square. Model 1 estimates the overall within-country variation, whereas Model 2 also includes time-fixed effects and further control variables.

Model 1 shows a significantly negative coefficient of the square of the log(telephone lines) variable, implying inverted U-shaped pattern between TFRs and technology diffusion. This means that within the emerging and developing countries in our sample, initial increases in the diffusion of technology come hand in hand with increases in TFRs, while from a certain technology level on, further increases in technology diffusion come hand in hand with decreases in TFRs. Note, however, that the estimated coefficient of the level of $\log$ (telephone lines) is significantly negative, which implies that the dominating pattern of the estimated within-country variation is the negative correlation between technology diffusion and fertility.

Figure 6 plots the overall within-country correlation between TFRs and the ten-year forward gap of $\log$ (telephone lines) that has been estimated by Model 1 against real observations (pooled data of cross-country and time series). Figure 6 illustrates a concave pattern between telephone lines and TFRs by confirming a maximum in the estimated correlation: at low technology levels, TFRs increase with an increasing diffusion of technology, while at higher technology levels, fertility decreases with further increases in the diffusion of technology. This estimation result is consistent with our theoretical prediction of an inverted U-shaped pattern of fertility in response to the increase in the level of technology as depicted in the upper graph of Figure 5. Figure 6 also shows that the dominating pattern in the estimated overall within-country variation is a negative correlation between fertility and technology diffusion, as the estimated turning point of the correlation pattern is situated at a relatively low level of technology diffusion. The maximum fertility level of 5.75 is reached a level of $\log$ (telephone lines) of -1.75, which corresponds to 0.17 telephone lines per 100 inhabitants. Around $6 \%$ of the observations are in the interval of a positive correlation between TFRs and telephone penetration following model $1 .{ }^{26}$

\footnotetext{
${ }^{25}$ Our theory works with an overlapping generations model in which each period lasts for 20 - 25 years, corresponding to the reproductive period of women or childhood period of children. Consistent with our theory, the proxy for technological progress should cover a certain period of time, and not only a point in time when we observe fertility. That is to say, fertility observed in year 1970 should not only depend on the contemporary diffusion of home appliances but also on the expected diffusion of home appliances in the following years. Given the time delay between the penetration of time-saving home appliances and the penetration of telephone lines, we choose a 10-year forward gap for the variable 'telephone lines' when estimating its correlation with fertility. Results are robust when using a 5-year and a 15-year forward gap instead of the 10-year forward gap. Results are available on request.

${ }^{26}$ The inverse U-shape is confirmed when using a reduced panel with observations until the year 1990 only. This robustness check was applied due to the fact that since the 1990s, telephone lines and other home appliances appear almost simultaneously in households.
} 


\begin{tabular}{|c|c|c|c|c|c|c|}
\hline & \multicolumn{6}{|c|}{ Total fertility rates } \\
\hline & M1 & M2 & M3 & M4 & M5 & M6 \\
\hline F10 of $\log$ (telephone lines) & $\begin{array}{l}-0.209 * * * \\
(0.0430)\end{array}$ & $\begin{array}{r}0.134 * \\
(0.0570)\end{array}$ & & & & \\
\hline F10 of $\log ^{2}$ (telephone lines) & $\begin{array}{c}-0.0598 * * * \\
(0.00912)\end{array}$ & $\begin{array}{c}-0.0799 * * * \\
(0.0102)\end{array}$ & & & & \\
\hline $\begin{array}{l}\log (\% \text { of population with } \\
\text { access to electricity })\end{array}$ & & & $\begin{array}{l}-0.209 * * * \\
(0.0254)\end{array}$ & $\begin{array}{l}-0.0307 \\
(0.0344)\end{array}$ & & \\
\hline $\begin{array}{l}\log ^{2}(\% \text { of population with } \\
\text { access to electricity })\end{array}$ & & & $\begin{array}{c}-0.127 * * * \\
(0.0135)\end{array}$ & $\begin{array}{c}-0.0469 * * * \\
(0.0112)\end{array}$ & & \\
\hline $\begin{array}{l}\log (\% \text { of households with } \\
\text { a refridgerator })\end{array}$ & & & & & $\begin{array}{l}-0.549 * * * \\
(0.159)\end{array}$ & $\begin{array}{l}-0.0102 \\
(0.198)\end{array}$ \\
\hline $\begin{array}{l}\log ^{2}(\% \text { of households with } \\
\text { a refridgerator })\end{array}$ & & & & & $\begin{array}{l}-0.0693+ \\
(0.0368)\end{array}$ & $\begin{array}{c}0.0145 \\
(0.0424)\end{array}$ \\
\hline $\log ($ GDP per capita $)$ & & $\begin{array}{l}-1.500+ \\
(0.823)\end{array}$ & & $\begin{array}{r}-1.925^{*} \\
(0.844)\end{array}$ & & $\begin{array}{l}-1.139 \\
(1.686)\end{array}$ \\
\hline $\log ^{2}$ (GDP per capita) & & $\begin{array}{l}0.0922 \\
(0.0567)\end{array}$ & & $\begin{array}{l}0.131 * \\
(0.0557)\end{array}$ & & $\begin{array}{l}0.0912 \\
(0.115)\end{array}$ \\
\hline Population density & & $\begin{array}{c}-0.00381 * * * \\
(0.000952)\end{array}$ & & $\begin{array}{l}-0.00203 * \\
(0.000791)\end{array}$ & & $\begin{array}{l}-0.00481 * * \\
(0.00163)\end{array}$ \\
\hline Exports in $\%$ of GDP & & $\begin{array}{l}0.000167 \\
(0.00227)\end{array}$ & & $\begin{array}{l}0.000224 \\
(0.00136)\end{array}$ & & $\begin{array}{l}-0.00222 \\
(0.00404)\end{array}$ \\
\hline Under 5-mortality rate & & $\begin{array}{c}0.00275 \\
(0.00251)\end{array}$ & & $\begin{array}{l}0.000373 \\
(0.00165)\end{array}$ & & $\begin{array}{l}-0.00356 \\
(0.00203)\end{array}$ \\
\hline Country fixed-effects & Yes & Yes & Yes & Yes & Yes & Yes \\
\hline Year fixed-effects & No & Yes & No & Yes & No & Yes \\
\hline Constant & $\begin{array}{l}5.600 * * * \\
(0.0384)\end{array}$ & $\begin{array}{l}12.15^{* * * *} \\
(3.009)\end{array}$ & $\begin{array}{c}6.517 * * * \\
(0.216)\end{array}$ & $\begin{array}{c}12.35 * * * \\
(3.246)\end{array}$ & $\begin{array}{c}6.395 * * * \\
(0.201)\end{array}$ & $\begin{array}{c}9.233 \\
(6.065)\end{array}$ \\
\hline Number of observations & 5592 & 3824 & 3561 & 3158 & 276 & 216 \\
\hline Number of countries & 148 & 137 & 150 & 137 & 76 & 65 \\
\hline Covered time period & $1960-2015$ & $1960-2015$ & $1990-2014$ & $1990-2014$ & $1990-2015$ & $1990-2015$ \\
\hline $\mathrm{R}^{2}$ adj. (within) & 0.635 & 0.775 & 0.377 & 0.73 & 0.167 & 0.411 \\
\hline
\end{tabular}

standard errors in parentheses; $+\mathrm{p}<0.1, * \mathrm{p}<0.05, * * \mathrm{p}<0.01, * * * \mathrm{p}<0.001$

Table 1: Total fertility rates as a function of technology diffusion. 


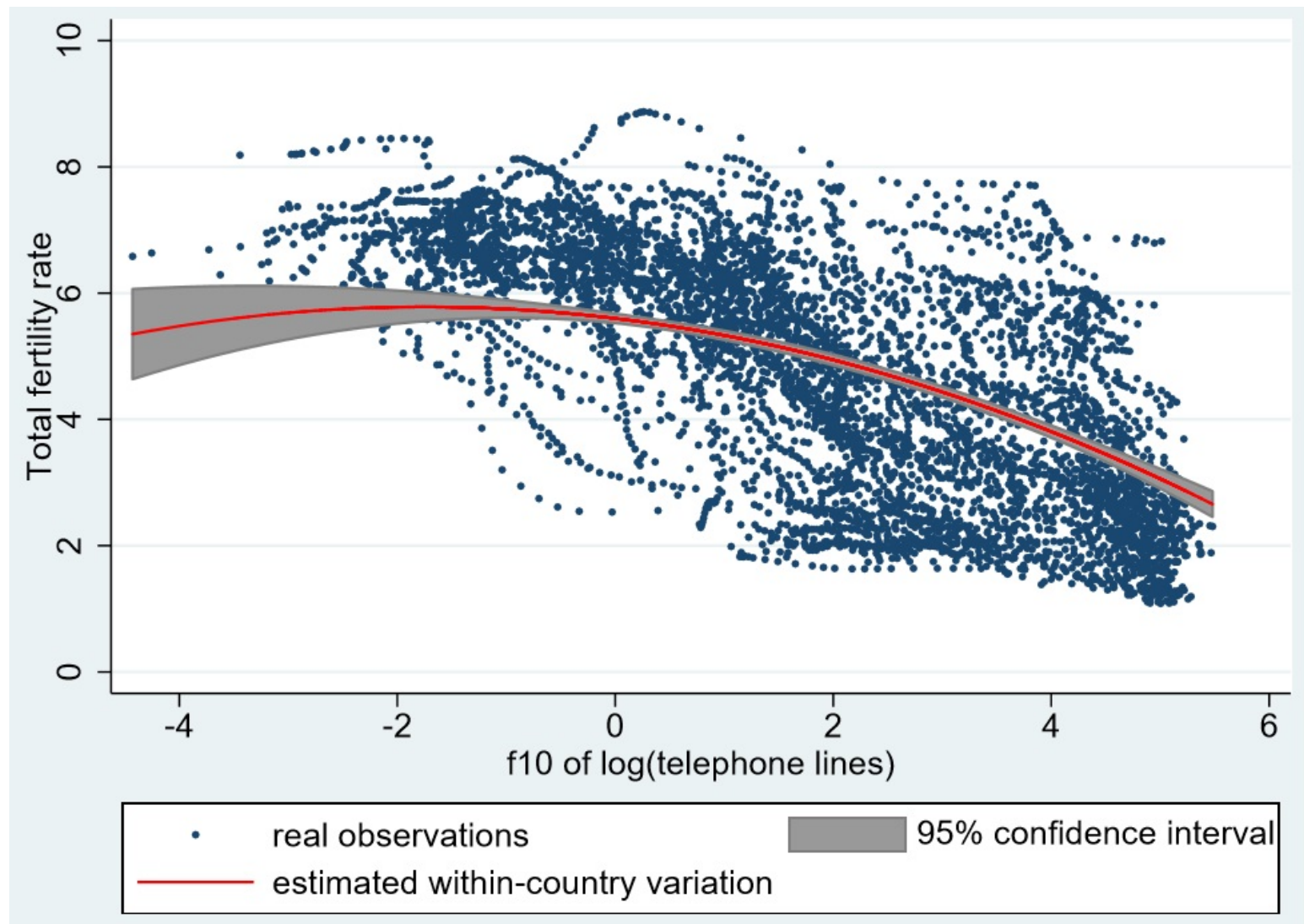

Figure 6: Fertility and density of telephone lines. Data: WB WDI, 148 countries, 1960-2015 $(N=5592)$.

The estimation results obtained by Model 1 and illustrated by Figure 6 can be quantified as follows: Increasing the $\log$ (telephone lines) by 1 unit from -2.8 (second percentile) to -1.8 (6th percentile) (i.e. from 0.1606 to 0.164 fixed and mobile telephone lines per 100 inhabitants) implies that TFRs increase by 0.13 children per women. Increasing the $\log$ (telephone lines) by 1 unit from 1.8 (50th percentile) to 2.8 (66th percentile) (i.e. from 6 to 17 fixed and mobile telephone lines per 100 inhabitants) implies that TFRs decrease by 0.42 children. $^{27}$

Model 2 in Table 1 shows that the estimated coefficient of the square of log(telephone lines) stays significantly negative when controlling for aggregate time trends, GDP per capita, population density and exports. This confirms the robustness of our finding of a concave within-country correlation pattern between fertility and technology diffusion. Note also that in Model 2, the estimated coefficient of $\log$ (telephone lines) is now smaller and positive. This suggests that once we include controls for time trends and variables that filter out technical advancement from other forms of progress, the estimated inverse U-shaped correlation pattern between fertility and telephone lines is no longer dominated by a declining branch. Model 2 suggests furthermore that within the developing and emerging countries of our sample, fertility decreases come hand in hand with increases in GDP per capita (10\% significance level) as well as with increases in population density. ${ }^{28}$

\footnotetext{
${ }^{27}$ Countries that are associated with the mentioned percentiles in our data set are for example: Benin in 1960 (second percentile), Tanzania in 1975 (sixth percentile), Hungary in 1980 (50th percentile) and Armenia in 1990 (66th percentile).

${ }^{28}$ We also tested for the indirect link that exists between telephone density and fertility due to the relative increase in female education. We therefore first estimated the ratio of female to male education as a function of telephone density (while controlling for population density and child mortality), and then estimated fertility in a second step, as a function of the estimated gender ratio in education, while we include population density and child mortality as control variables. Our results suggest that an access of parents to time-saving home appliances
} 
The third and fourth column of Table 1 present regression results of TFRs estimated as a function of $\log (\%$ of population with access to electricity) and its square. Model 3 estimates the overall withincountry variation, whereas in Model 4, time-fixed effects and controls are included. Both Models 3 and 4 confirm a concave within-country variation between TFRs and our second proxy for time-saving home appliances, namely access to electricity.

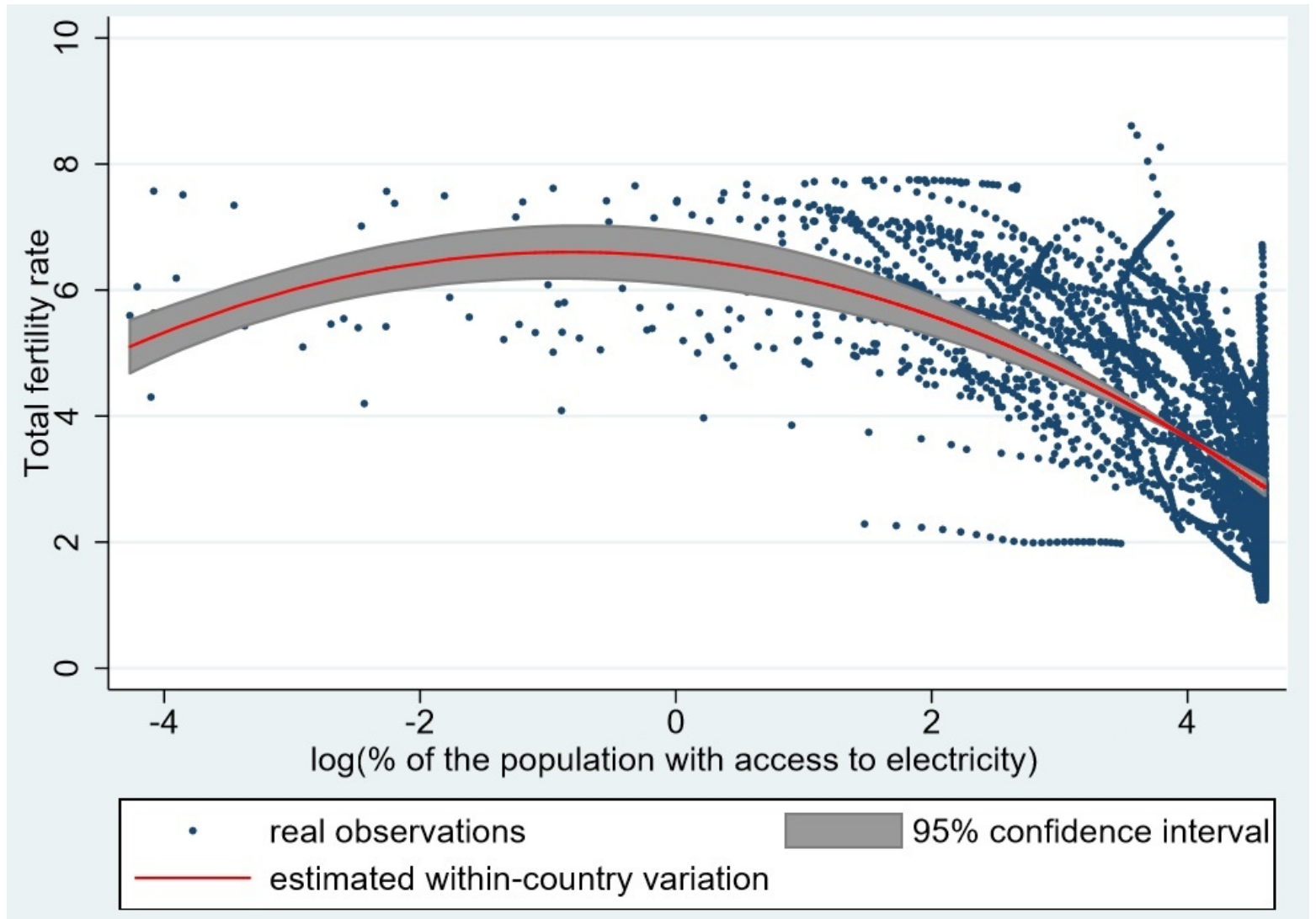

Figure 7: Fertility and access to electricity. Data: WB WDI, 150 countries, 1990-2014 $(N=3561)$.

Figure 7 illustrates the estimated overall within-country correlation based on Model 3. The correlation pattern is again inverted U-shaped, suggesting that fertility first increases with access to technology at lower technological levels and then decreases with the further diffusion of technology. Figure 7 also plots the real observations, illustrating the much lower number of observations in comparison to Figure 6. This lower number is due to the late appearance of the time series data on access to electricity, which explains the accumulation of observations at relatively high electricity levels (a log of 'electricity' of 4.6 corresponds to $100 \%$ of electricity coverage). Indeed, in the $1990 \mathrm{~s}$, most countries —even the least developed ones - had already experienced their peak of fertility and many more developed countries have already completed their demographic transitions with stable and low fertility rates. A comparison of Models 3 and 4 reveals -similar to what we have found when using telephone lines as a proxy for time-saving home appliances- that the declining branch of the inverse U-shaped correlation pattern between fertility and access to electricity is somewhat dominating, while this is no longer the case once we control for time-fixed effects, GDP per capita, exports, population density and child mortality:

leads to relative increases in their daughters' education, which later on leads to decreases in TFRs within developing and emerging countries. Subsequent impacts are taken into account by allowing for a certain time delay between the observed technology level, the education and the fertility outcomes. Results are available upon request. 
While the coefficient of the square of our electricity variable is significantly negative in both models, Model 4 shows that the coefficient of electricity itself is not significant in comparison to Model 3.

Models 5 and 6 of Table 1 show regression results of TFRs estimated as a function of $\log (\%$ of households with a refrigerator) and its square. Model 5 is the simple model with country-fixed effects only, while Model 6 also contains time-fixed effects and control variables. The number of observations used here is extremely reduced due to the limited time and country coverage of the DHS. Model 5 suggests a concave overall within-country correlation between TFRs and our third proxy for timesaving home appliances, i.e. the di usion of refrigerators. The concavity is, however, only significant on a $10 \%$ level, and disappears once we add time-fixed effects and controls to the estimation model (Model 6). Figure 8 illustrates that the estimated overall within-country correlation pattern between fertility and refrigerator diffusion is slightly concave, albeit with a more dominant negative pattern in comparison to Figures 6 and 7. The weak within-country estimation results are likely to be caused by the fact that data on refrigerator diffusion in the DHS is not available for every year and observations are very unevenly distributed over time. On average, each country has only 3.6 observed time periods in the DHS. For comparison, the average number of observations per country is 38 in Model 1 (telephone diffusion) and 25 in Model 3 (access to electricity).

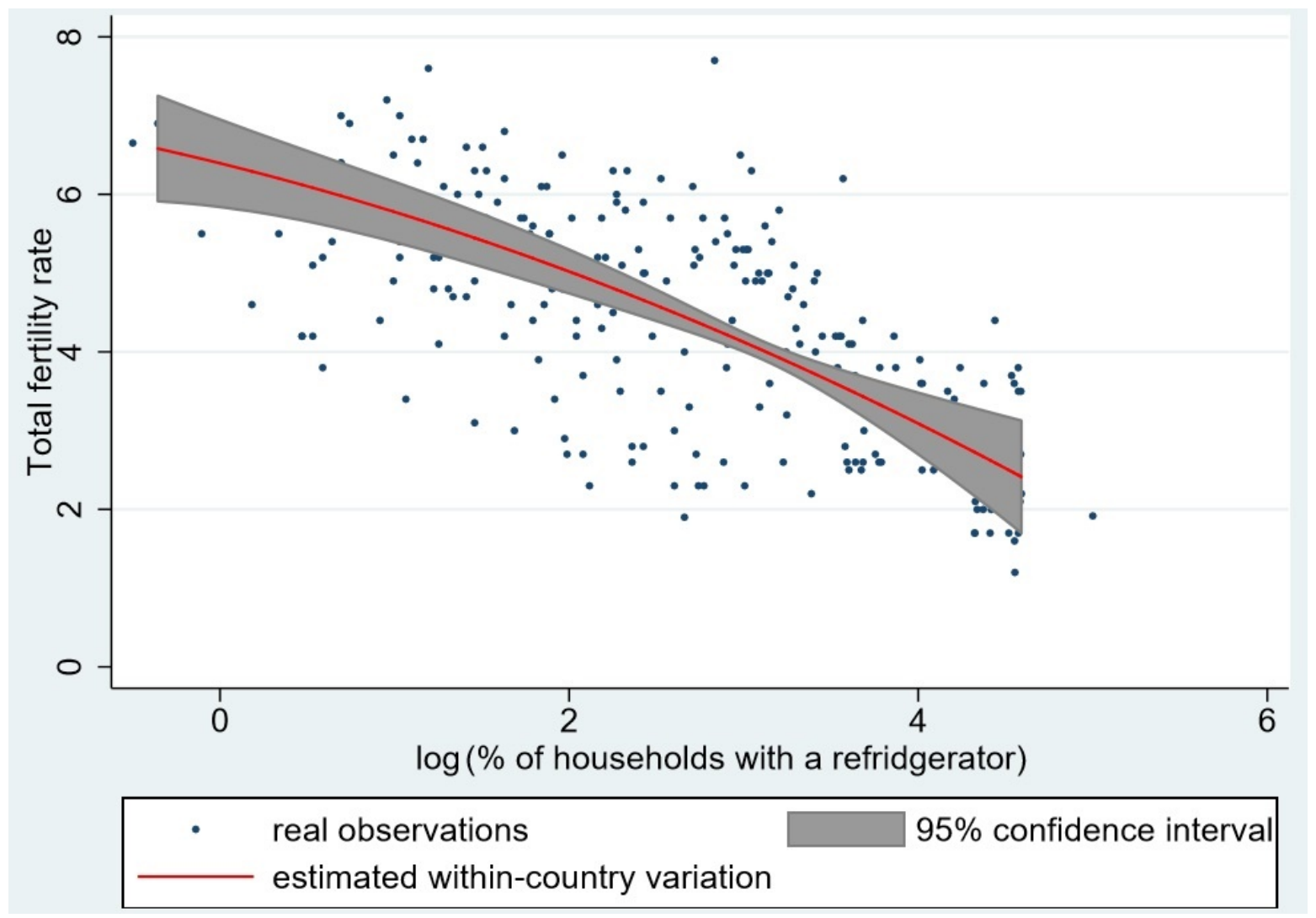

Figure 8: Fertility and refrigerator diffusion. Data: DHS, 76 countries, 1990-2015 $(N=276)$.

\subsection{The effect of home appliances on the gender gap in education}

Models 7 and 8 in Table 2 present regression results of the gender gap in education, estimated as a function of $\log$ (telephone lines) and its square. The gender gap in education is measured by the 
female-to-male ratio of average years of total schooling for ages 20-24.

Access to telephone lines, which figures here as a proxy for access to time-saving home appliances one decade before, allows parents to send their children, and especially girls, to school, when they are around ten to fifteen years old. The telephone density that we observe at the time when the children are aged 20-24 gives us thus information about the parental access to time-saving home appliances 10 years earlier, i.e. when their children were 10 to 15 years old. Thus, in this setting, we do not need a forward gap for telephone lines when empirically investigating the correlation between telephone lines and the gender gap in education.

\begin{tabular}{|c|c|c|c|c|}
\hline & \multicolumn{2}{|c|}{$\begin{array}{l}\text { Ratio of female-to-male years of } \\
\text { schooling (ages 20-24) }\end{array}$} & \multicolumn{2}{|c|}{$\begin{array}{c}\% \text { of women in wage employment in } \\
\text { nonagricultural sector }\end{array}$} \\
\hline & M7 & M8 & M9 & M10 \\
\hline $\log ($ telephone lines) & $\begin{array}{l}0.0877 * * * \\
(0.00703)\end{array}$ & $\begin{array}{l}0.00759 \\
(0.0105)\end{array}$ & $\begin{array}{l}1.105 * * * \\
(0.328)\end{array}$ & $\begin{array}{c}0.756 \\
(0.532)\end{array}$ \\
\hline $\log (\text { telephone lines })^{2}$ & $\begin{array}{c}-0.00973 * * * \\
(0.00158)\end{array}$ & $\begin{array}{r}-0.00645^{*} \\
(0.00269)\end{array}$ & $\begin{array}{l}-0.0325 \\
(0.0508)\end{array}$ & $\begin{array}{l}-0.184 * \\
(0.0798)\end{array}$ \\
\hline $\log$ (GDP per capita) & & $\begin{array}{l}0.0620 \\
(0.144)\end{array}$ & & $\begin{array}{l}-5.339 \\
(5.847)\end{array}$ \\
\hline $\log (\text { GDP per capita })^{2}$ & & $\begin{array}{l}-0.00741 \\
(0.00982)\end{array}$ & & $\begin{array}{c}0.165 \\
(0.369)\end{array}$ \\
\hline Population density & & $\begin{array}{l}0.000429 * \\
(0.000170)\end{array}$ & & $\begin{array}{c}-0.0117 \\
(0.00962)\end{array}$ \\
\hline Exports in \% of GDP & & $\begin{array}{l}0.000170 \\
(0.000554)\end{array}$ & & $\begin{array}{l}-0.00445 \\
(0.0139)\end{array}$ \\
\hline Under 5-mortality rate & & $\begin{array}{l}-0.000607 \\
(0.000383)\end{array}$ & & $\begin{array}{l}0.00241 \\
(0.0158)\end{array}$ \\
\hline Total fertility rate & & $\begin{array}{c}-0.0387 * * \\
(0.0130)\end{array}$ & & $\begin{array}{l}-0.237 \\
(0.463)\end{array}$ \\
\hline Country fixed-effects & Yes & Yes & Yes & Yes \\
\hline Year fixed-effects & No & Yes & No & Yes \\
\hline Constant & $\begin{array}{l}0.785 * * * \\
(0.00581)\end{array}$ & $\begin{array}{l}0.924 \\
(0.579)\end{array}$ & $\begin{array}{c}33.91 * * * \\
(0.520)\end{array}$ & $\begin{array}{l}67.54 * * \\
(23.74)\end{array}$ \\
\hline Number of observations & 963 & 747 & 1428 & 1347 \\
\hline Number of countries & 100 & 99 & 142 & 132 \\
\hline Covered time period & $\begin{array}{c}1960-2010 \\
(5 \text { year intervals) }\end{array}$ & $\begin{array}{c}1960-2010 \\
\text { (5 year intervals) }\end{array}$ & $1990-2013$ & $1990-2013$ \\
\hline $\mathrm{R}^{2}$ (within) & 0.471 & 0.587 & 0.227 & 0.358 \\
\hline
\end{tabular}

standard errors in parentheses; ${ }^{*} \mathrm{p}<0.05,{ }^{* *} \mathrm{p}<0.01,{ }^{* * *} \mathrm{p}<0.001$

Table 2: The gender gap in education and female formal labor force participation as a function of technology diffusion. 


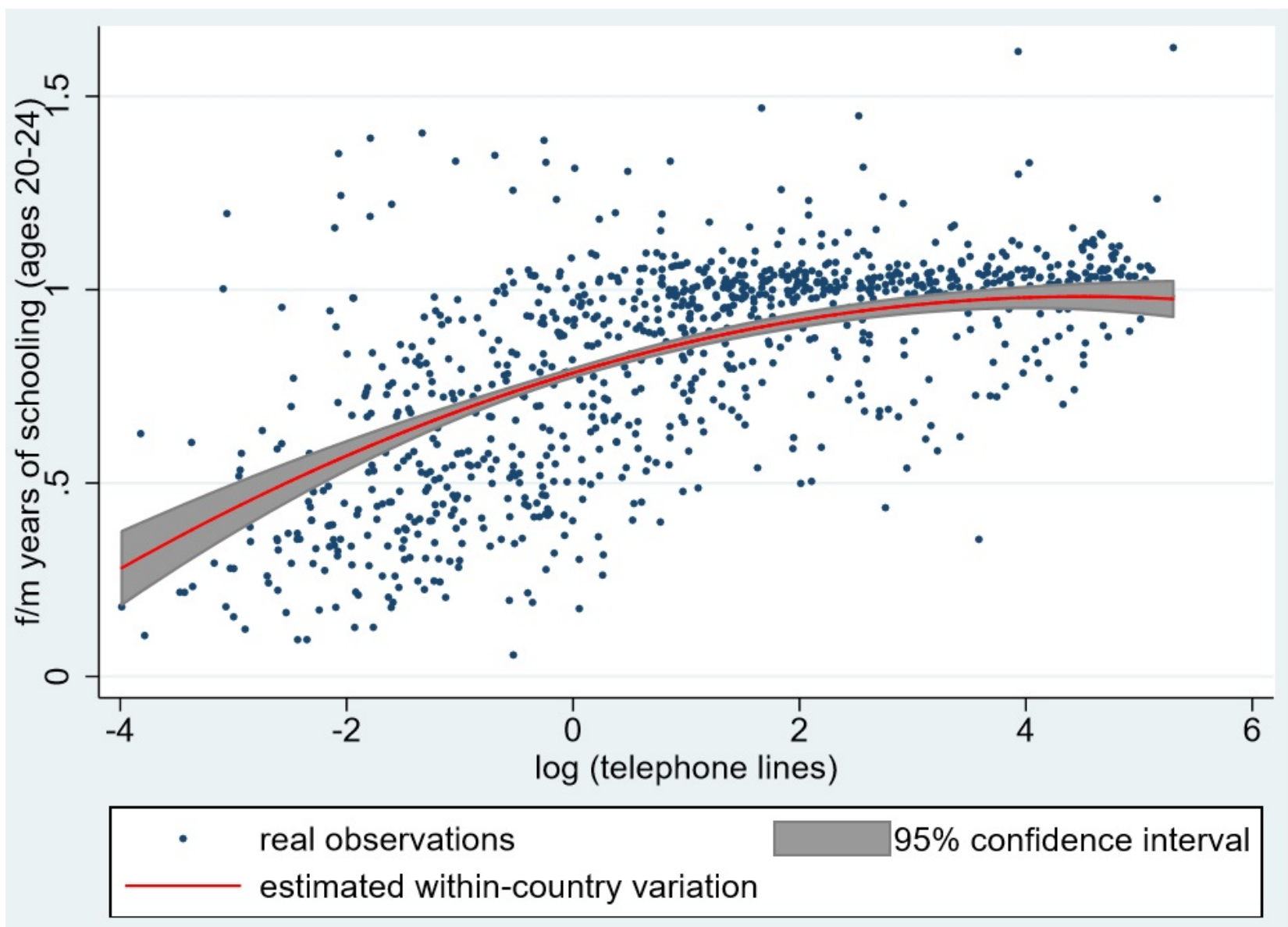

Figure 9: Female/male years of schooling (ages 20 to 24) and density of telephone lines. Data: WB WDI and Barro \& Lee (2013), 100 countries, 1960-2010; 5-year intervals $(N=963)$.

Model 7 contains country-fixed effects and therewith estimates the overall within-country variation, whereas Model 8 also includes time-fixed effects and control variables (GDP per capita and its square, exports, population density, child mortality, and TFRs).

Both models suggest a concave within-country correlation between telephone lines and the gender ratio in education, as the estimated coefficient of the square of $\log$ (telephone lines) is significantly negative. Figure 9 illustrates the estimated overall within-country variation as estimated by Model 7 , and contrasts it to real observations. The figure shows a concave pattern between telephone lines and the gender ratio in education with a dominating rising branch: the female to male ratio in education increases with an initial increase in telephone density, and then stagnates at higher levels of access to telephone lines. The ratio actually converges around 1 (i.e. gender equality in education) once a certain level of technological advancement is achieved. This is in line with our theoretical prediction about the improvement of gender equality in education in response to an increase in the level of technology, as depicted in Figure 4. Further controls, which confirm the robustness of our findings are available on request. They include alternative measures of education (for example the female to male ratio of years of total schooling for ages $20-24$, with the female to male ratio of years of total schooling for ages $15+$ ) and different time gaps for "telephone lines". 


\subsection{The effect of home appliances on female formal labor-force participation}

Regression results of the female formal labor-force participation estimated as a function of log(telephone lines) and its square can be found in the last two columns of Table 2. Model 9 only contains countryfixed effects while model 10 also contains time-fixed effects and further controls.

For this empirical investigation, we prefer formal employment over general employment measures including informal employment and subsistence activities, as female formal employment has the technical advantage that it evolves uniformly more or less during the process of economic development (and therewith over time), whereas women's general labor market participation is known to follow a U-shaped pattern (i.e. decrease first with initial stages of economic development, see "feminization U" hypothesis by Goldin (1995)).

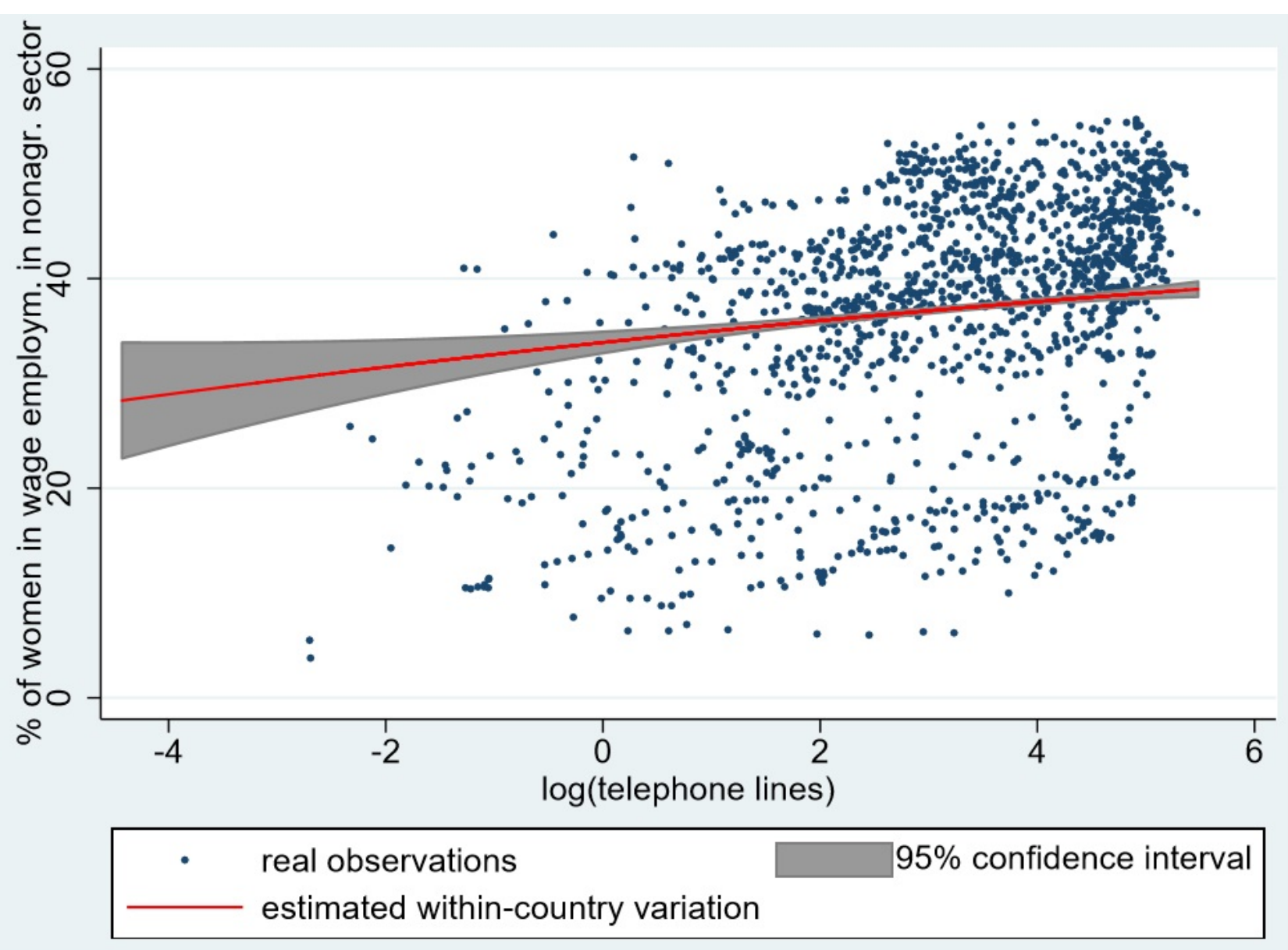

Figure 10: The percentage of women in wage employment in the nonagricultural sector and density of telephone lines. Data: WB WDI, 142 countries, 1990-2013 $(N=1248)$.

Formal female employment is measured by the share of women in wage-employment in the nonagricultural sector, for which data is available for the 1990s onwards only. In order to keep the data set as large as possible, we abstain here from using forward gaps of the exogenous variable 'telephone lines'.

Here, only the full model (Model 10) suggest a slightly concave within-country correlation between telephone lines and the female formal market participation, as the estimated coefficient of the square 
of $\log$ (telephone lines) is significantly negative. Model 9, which does not include further controls and therewith estimates the overall within-country pattern, rather suggests a positive correlation, which is illustrated by Figure 10 .

It seems thus that overall within developing and emerging countries, increases in access to telephone lines are positively correlated with increases in female formal wage employment for initial stages of technological advancement, while levels of formal female wage employment stagnate at relatively high levels of technological advancement. This is consistent with our theoretical prediction of an increase in female labor force participation, in response to an increase in the level of technology, as depicted in the lower graph of Figure 5.

\section{Concluding remarks}

This paper has introduced a model in the tradition of unified growth theory to uncover a new mechanism linking the demographic transition and the onset of sustained growth to the decline in the education gender gap. It has argued that the impact of technological progress on the efficiency of household production triggered an increase in female labor force participation, narrowing the education gender gap and triggering a fertility decline. In turn, the subsequent increase in the average human capital fosters further technological progress creating a feedback loop able to trigger sustained growth. Along the way, fertility increases first, as women's time is freed up, enabling additional child-rearing, while it eventually decreases, after increased labor force participation raises education investment in daughters and hence their opportunity cost of childrearing. The model predictions have been tested against evidence from emerging and developing countries having undergone a demographic transition, and it has helped to explain some stylized facts characterizing the development process.

Specifically, the paper sheds light on the transition - from stagnation to sustained growth, through a demographic transition - experienced by developing countries in the late 20th and early 21st centuries. The paper also shows that technological progress may increase female labor market participation, not only by freeing women's time from housework due to the appearance of time-saving householdsector products, but also by leading households to reduce fertility due to an increase in the return of women's human capital, which increases the opportunity cost of raising children. In addition, technological progress makes households substitute quality to quantity in their fertility choice. Finally, the paper provides empirical evidence to validate the main predictions of the model about the effects of technological progress, through the creation and spread of labor-saving home appliances, on fertility and education investment across genders, as well as on formal female labor-force participation.

\section{Appendix}

\section{A0. Household's first-order conditions}

The first-order conditions of the household's problem are 


$$
\left(\begin{array}{c}
U_{c}^{t} \\
U_{n}^{t} \\
U_{e}^{t} \\
U_{\tilde{e}}^{t}
\end{array}\right)=\lambda_{1}\left(\begin{array}{c}
1 \\
\rho w_{t} \tilde{e}_{t-1}^{\theta}+e_{t}+\tilde{e}_{t} \\
n_{t} \\
n_{t}
\end{array}\right)+\lambda_{2}\left(\begin{array}{c}
0 \\
0 \\
-1 \\
0
\end{array}\right)+\lambda_{3}\left(\begin{array}{c}
0 \\
0 \\
0 \\
-1
\end{array}\right)+\lambda_{4}\left(\begin{array}{l}
0 \\
\rho \\
0 \\
0
\end{array}\right)
$$

along with the constraints and the slackness conditions, for multipliers $\lambda_{i} \geq 0$, where $U_{j}^{t}$ are the marginal utilities. Accordingly, households choose education investments to equalize the marginal utilities of their sons' and daughters' human capitals, as well as fertility and consumption, in order to equalize the marginal rate of substitution of consumption and fertility with the marginal cost of the latter. Thus, depending on whether the time constraint is binding, the household's choice on education and fertility is

$$
\begin{gathered}
e_{t}=\left\{\begin{array}{ccc}
\frac{\gamma \theta}{1-\gamma+\gamma \theta} \frac{\rho}{\left(1-\phi_{t}\right)\left[1+\left(1-\phi_{t+1}\right)^{\frac{1}{1-\theta}}\right]} w_{t} e_{t-1}^{\theta} & \text { if } & \phi_{t}+\rho n_{t}=1 \\
\frac{\theta}{1-\theta} \frac{\rho}{1+\left(1-\phi_{t+1}\right)^{\frac{1}{1-\theta}}} w_{t} \tilde{e}_{t-1}^{\theta} & \text { if } & \phi_{t}+\rho n_{t}<1
\end{array}\right. \\
\tilde{e}_{t}=\left\{\begin{array}{ccc}
\frac{\gamma \theta}{1-\gamma+\gamma \theta} \frac{\rho}{\left(1-\phi_{t}\right)\left[1+\left(1-\phi_{t+1}\right)^{\frac{1}{\theta-1}}\right]} w_{t} e_{t-1}^{\theta} & \text { if } & \phi_{t}+\rho n_{t}=1 \\
\frac{\theta}{1-\theta} \frac{\rho}{1+\left(1-\phi_{t+1}\right)^{\frac{1}{\theta-1}}} w_{t} \tilde{e}_{t-1}^{\theta} & \text { if } & \phi_{t}+\rho n_{t}<1
\end{array}\right. \\
n_{t}=\min \left\{\frac{1-\phi_{t}}{\rho}, \frac{\gamma(1-\theta)}{\rho}\left[\frac{e_{t-1}^{\theta}}{\tilde{e}_{t-1}^{\theta}}+1-\phi_{t}\right]\right\}
\end{gathered}
$$

so that the fertility in the binding and non-binding cases coincide for some $\phi_{t}$, i.e.

$$
\frac{\gamma(1-\theta)}{\rho}\left[\frac{e_{t-1}^{\theta}}{\tilde{e}_{t-1}^{\theta}}+1-\phi_{t}\right]=\frac{1-\phi_{t}}{\rho}
$$

but, since from (16) and (17) it holds in any period $t-1$

$$
\frac{e_{t-1}^{\theta}}{\tilde{e}_{t-1}^{\theta}}=\left[\frac{1+\left(1-\phi_{t}\right)^{\frac{1}{\theta-1}}}{1+\left(1-\phi_{t}\right)^{\frac{1}{1-\theta}}}\right]^{\theta}=\left(1-\phi_{t}\right)^{\frac{\theta}{\theta-1}},
$$

then (19) implies that the time constraint will be binding whenever

$$
\phi_{t}=1-\left[\frac{\gamma(1-\theta)}{1-\gamma(1-\theta)}\right]^{1-\theta}
$$

for which the binding and non-binding consumption and education choices coincide.

\section{A1. Proof of Lemma 1}

Let us denote $E_{t-1}=e_{t-1}+\tilde{e}_{t-1}$, which is determined in period $t-1$ as in (13). The growth rate of technological progress between periods $t$ and $t+1$ is

$$
g_{t}=g\left(\frac{e_{t-1}^{\theta}+\tilde{e}_{t-1}^{\theta}}{2}\right)=g\left(\frac{\left(E_{t-1}-\tilde{e}_{t-1}\right)^{\theta}+\tilde{e}_{t-1}^{\theta}}{2}\right)
$$


so that

$$
\frac{\partial g_{t}}{\partial \tilde{e}_{t-1}}=g^{\prime}\left(\frac{\left(E_{t-1}-\tilde{e}_{t-1}\right)^{\theta}+\tilde{e}_{t-1}^{\theta}}{2}\right) \frac{\theta}{2}\left[\tilde{e}_{t-1}^{\theta-1}-\left(E_{t-1}-\tilde{e}_{t-1}\right)^{\theta-1}\right]
$$

Since $g^{\prime}()>$.0 and $\theta \in(0,1)$ then $\partial g_{t} / \partial \tilde{e}_{t-1}>(=)(<) 0 \Leftrightarrow \tilde{e}_{t-1}<(=)(>) E_{t-1} / 2$, which implies the result stated in Lemma 1.

\section{A2. Proof of Lemma 2}

Since $\lim _{t \rightarrow+\infty} m_{t}=m>0$ then $\forall \varepsilon \in(0, m), \exists T$ such that $\forall t \geq T$, we have

$$
m-\varepsilon \leq m_{t} \leq m+\varepsilon
$$

Define

$$
X_{0}=Q_{0}=Z_{0}=x_{T}
$$

and

$$
X_{t+1}=m_{T+t} X_{t}^{\alpha}, \quad Q_{t+1}=(m+\varepsilon) Q_{t}^{\alpha}, \quad Z_{t+1}=(m-\varepsilon) Z_{t}^{\alpha}
$$

We know that

$$
\lim _{t \rightarrow+\infty} Q_{t}=(a+\varepsilon)^{\frac{1}{1-\alpha}} \quad \text { and } \quad \lim _{t \rightarrow+\infty} Z_{t}=(a-\varepsilon)^{\frac{1}{1-\alpha}}
$$

We also have

$$
\begin{gathered}
Z_{1}=(m-\varepsilon) X_{0}^{\alpha} \leq X_{1}=m_{T} X_{0}^{\alpha} \leq(m+\varepsilon) X_{0}^{\alpha}=Q_{1} \\
Z_{2}=(m-\varepsilon) Z_{1}^{\alpha} \leq(m-\varepsilon) X_{1}^{\alpha} \leq X_{2}=m_{T+1} X_{1}^{\alpha} \leq(m+\varepsilon) X_{1}^{\alpha} \leq(m+\varepsilon) Q_{1}^{\alpha}=Q_{2}
\end{gathered}
$$

and so on, by induction we have $Z_{t} \leq X_{t} \leq Q_{t}, \forall t$. Hence,

$$
(m-\varepsilon)^{\frac{1}{1-\alpha}}=\lim _{t \rightarrow+\infty} Z_{t} \leq \lim _{T \rightarrow+\infty}\left(\inf _{t \geq T} X_{t}\right) \leq \lim _{T \rightarrow+\infty}\left(\sup _{t \geq T} X_{t}\right) \leq \lim _{t \rightarrow+\infty} Q_{t}=(m+\varepsilon)^{\frac{1}{1-\alpha}}
$$

That is to say

$$
(m-\varepsilon)^{\frac{1}{1-\alpha}} \leq \lim _{T \rightarrow+\infty}\left(\inf _{t \geq T} X_{t}\right) \leq \lim _{T \rightarrow+\infty}\left(\sup _{t \geq T} X_{t}\right) \leq(m+\varepsilon)^{\frac{1}{1-\alpha}}, \forall \varepsilon \in(0, m)
$$

Hence,

$$
\lim _{\varepsilon \rightarrow 0^{+}}(m-\varepsilon)^{\frac{1}{1-\alpha}} \leq \lim _{T \rightarrow+\infty}\left(\inf _{t \geq T} X_{t}\right) \leq \lim _{T \rightarrow+\infty}\left(\sup _{t \geq T} X_{t}\right) \leq \lim _{\varepsilon \rightarrow 0^{+}}(m+\varepsilon)^{\frac{1}{1-\alpha}}
$$


i.e.

$$
m^{\frac{1}{1-\alpha}} \leq \lim _{T \rightarrow+\infty}\left(\inf _{t \geq T} X_{t}\right) \leq \lim _{T \rightarrow+\infty}\left(\sup _{t \geq T} X_{t}\right) \leq m^{\frac{1}{1-\alpha}}
$$

which implies

$$
\lim _{t \rightarrow+\infty} X_{t}=m^{\frac{1}{1-\alpha}}, \quad \text { i.e. } \quad \lim _{t \rightarrow+\infty} x_{t}=m^{\frac{1}{1-\alpha}}
$$

\section{A3. Reversal in the education gap across genders}

Following Goldin et al. (2006) and Becker et al. (2010) on heterogeneity in non-cognitive skills across genders, we can modify the human capital formation function for women to be $\tilde{\psi} \tilde{e_{t}}{ }^{\theta}$ with $\tilde{\psi}>1$, while the human capital formation function for men remains unchanged. The parameter $\tilde{\psi}$ gauges the noncognitive skills advantage of an average daughter. Also, let a man's income with education $e_{t-1}$ be $w_{t}\left(\psi+e_{t-1}^{\theta}\right)$ in period $t$, where $\psi>0$ captures the gender discrimination because of men's physical strength and no career interruptions linked to paternity. This allows capturing the fact that, with the same levels of education, men usually receive higher wages than women.

The household's optimization problem then becomes

$$
\max _{c_{t}, n_{t}>0, e_{t}, \tilde{e}_{t} \geq 0}(1-\gamma) \ln c_{t}+\gamma \ln \left(n_{t} w_{t+1}\left[\psi+e_{t}^{\theta}+\left(1-\phi_{t+1}\right) \tilde{\psi} \tilde{e}_{t}^{\theta}\right]\right)
$$

subject to

$$
\begin{gathered}
c_{t}+n_{t}\left(e_{t}+\tilde{e}_{t}\right) \leq w_{t}\left[\psi+e_{t-1}^{\theta}+\left(1-\phi_{t}-\rho n_{t}\right) \tilde{\psi} \tilde{e}_{t-1}^{\theta}\right] \\
\phi_{t}+\rho n_{t} \leq 1
\end{gathered}
$$

- note that the potential incomes of sons $w_{t+1}\left(\psi+e_{t}^{\theta}\right)$ consists of two parts, the potential basic, unskilled labor income $w_{t+1} \psi$ and the potential skilled labor income $w_{t+1} e_{t}^{\theta}$. At the solution to the optimization problem above, the gender inequality in education $\mu_{t}$ is determined by

$$
\mu_{t}=\frac{\tilde{e}_{t-1}}{e_{t-1}}=\left[\left(1-\phi\left(a_{t}\right)\right) \tilde{\psi}\right]^{\frac{1}{1-\theta}} \equiv \tilde{\mu}\left(a_{t}\right)
$$

with, from Assumption 1,

$$
\tilde{\mu}^{\prime}(a)>0 \quad \text { and } \quad \lim _{a \rightarrow+\infty} \tilde{\mu}(a)=\tilde{\psi}^{\frac{1}{1-\theta}}>1
$$

The following assumption further guarantees that for low levels of technology, the education investment in daughters is lower than in sons.

Assumption 3. $(1-\bar{\phi}) \tilde{\psi}<1$.

Thus, the following lemma states that the reversal in education investment across genders, for a high level of technology follows straightforwardly from Assumption 3 and the properties of $\tilde{\mu}\left(a_{t}\right)$ in $(22)$.

Lemma 3. Under assumptions 1 and 3, there exists a unique level of technology $\tilde{a}>0$ at which $\tilde{\mu}(\tilde{a})=1$ so that complete equality in education investment across genders holds. Moreover, for all a $\in(0, \tilde{a})$ it holds $\tilde{\mu}(a)<1$, and for all $a>\tilde{a}, \tilde{\mu}(a)>1$. 


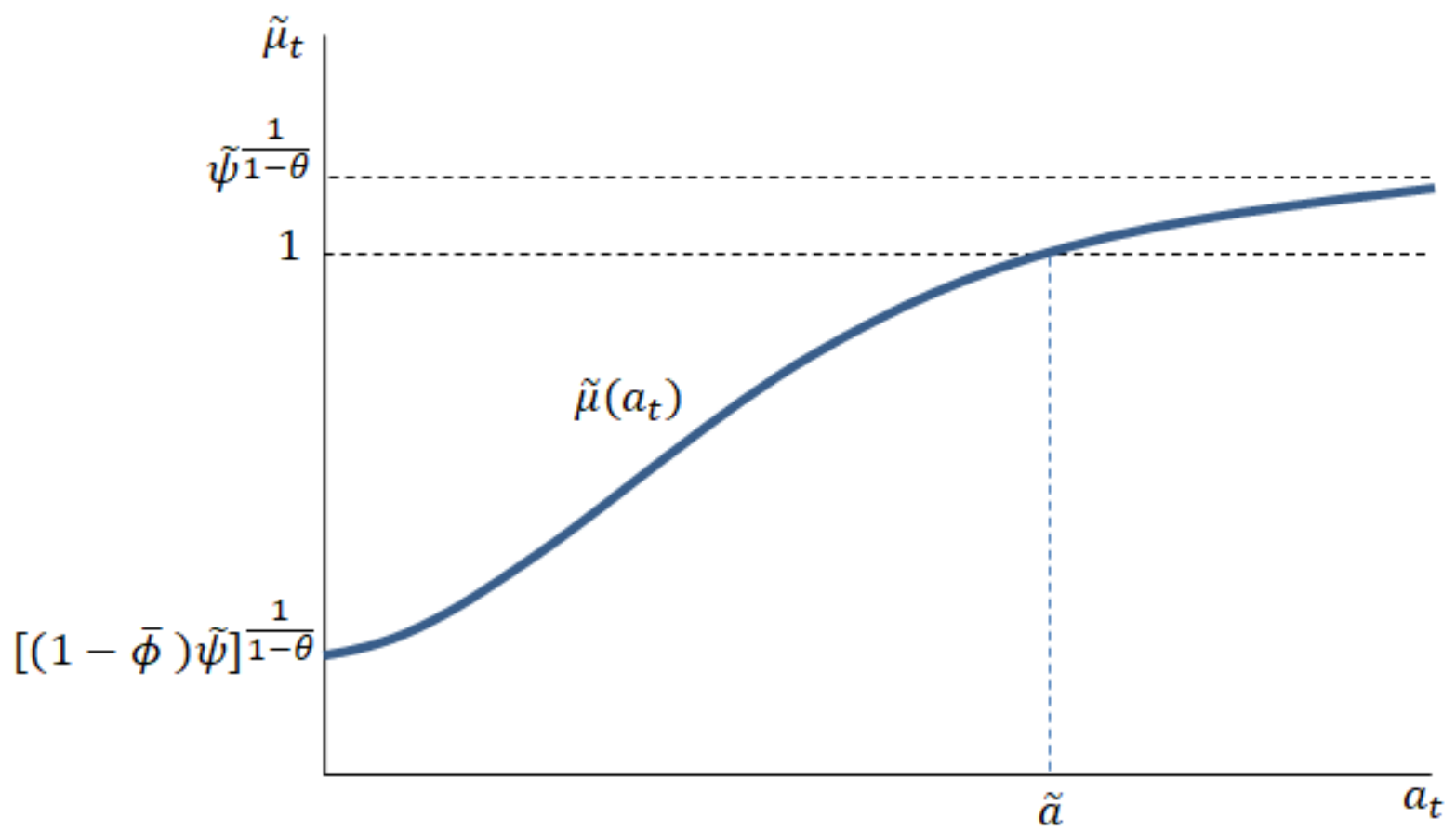

Figure 11: Reversal in education investment across genders.

In other words, during the development process, and along with the technological progress, the education investment in daughters increases relative to that in sons, and a reversal in the education investment gap across genders occurs with a sufficiently high level of technology. The reasoning here is quite intuitive. Technological progress makes parents invest relatively more in their daughters' education when the marginal return to education investment in daughters is greater than in sons. So whenever the technology surpasses a tipping point $\tilde{a}$ above which the potential income of the daughter is greater than the potential skilled labor income of the son, the parents will optimally invest more in the education for their daughter than for their son, in order to equalize the marginal utility from an increase in the education of either child. Thus, the daughter's education eventually exceeds the son's. ${ }^{29}$

\section{A4. Correlation matrix and summary of data on next pages}

\footnotetext{
${ }^{29}$ Note that, what we observe from the data is the reversal in education achievement $-e_{t}^{\theta}$ and $\tilde{\psi} \tilde{e}^{\theta}$ for sons and daughters respectively - rather than education investment. Assumption 1 and $\tilde{\psi}>1$ are sufficient for a reversal in education investment across genders, i.e. $\lim _{a \rightarrow+\infty} \tilde{\mu}(a)=\lim _{a \rightarrow+\infty}[(1-\phi(a)) \tilde{\psi}]^{\frac{1}{1-\theta}}=\tilde{\psi}^{\frac{1}{1-\theta}}>1$. Such a reversal, however, can occur for the education achievement even if there is not any in education investment, i.e. when $\lim _{a \rightarrow+\infty}[(1-\phi(a)) \tilde{\psi}]^{\frac{1}{1-\theta}}=1$. Indeed, as proved in Proposition $2, e=\lim _{t \rightarrow+\infty} e_{t}=\lim _{t \rightarrow+\infty} \tilde{e}_{t}=\tilde{e}$. As a consequence, eventually $e^{\theta}<\tilde{\psi} \tilde{e}^{\theta}$, so that the education achievement of the daughter exceeds that of the son even if the daughter's education investment does not. That is to say, when the level of technology is sufficiently high the education achievement will reverse across genders because of both (i) the improvement in gender equality in education investment and (ii) the better efficiency of female education investment.
} 


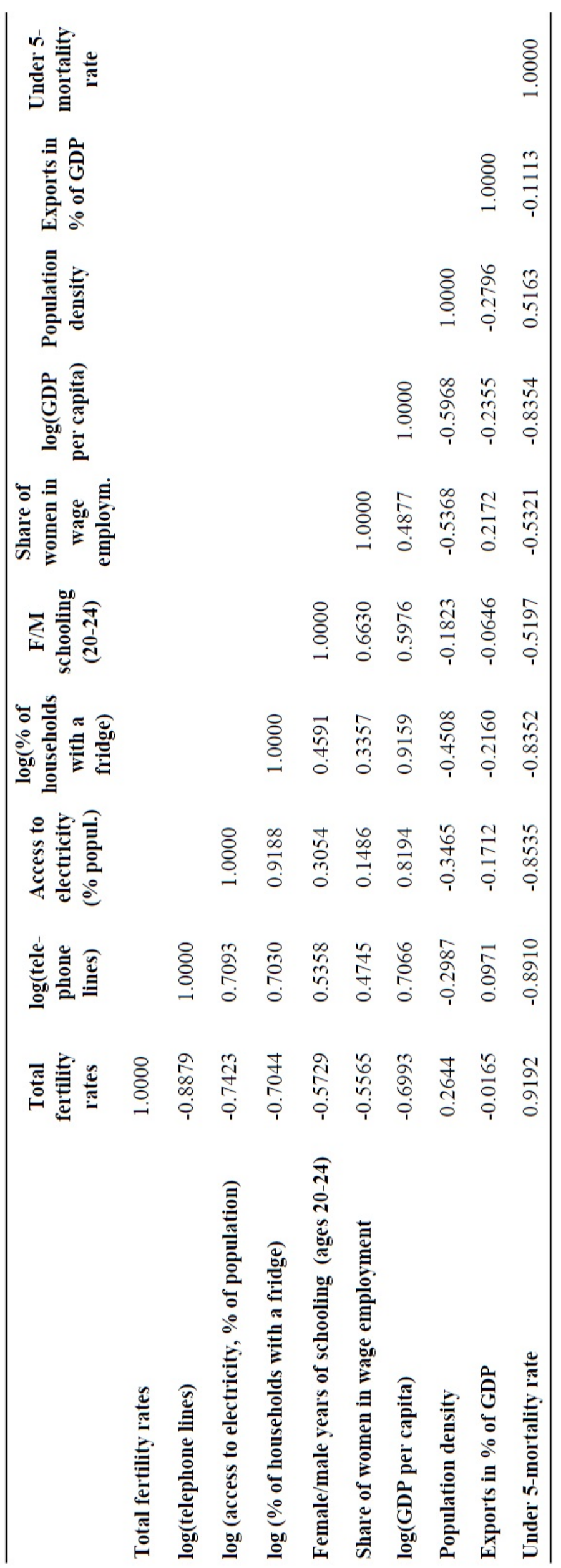


窇

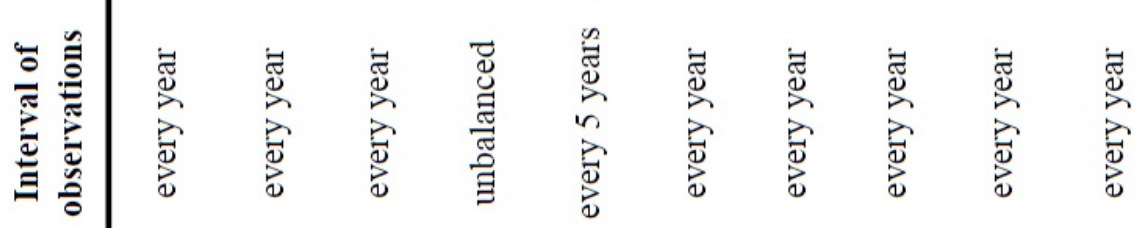

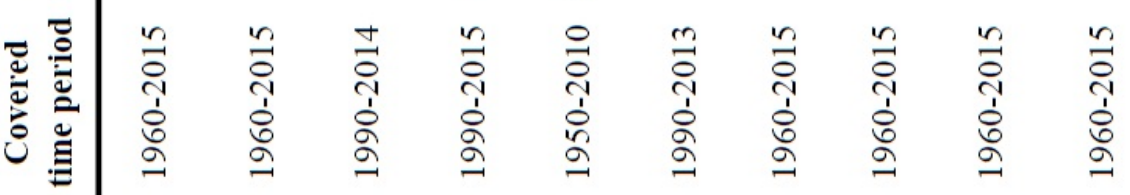

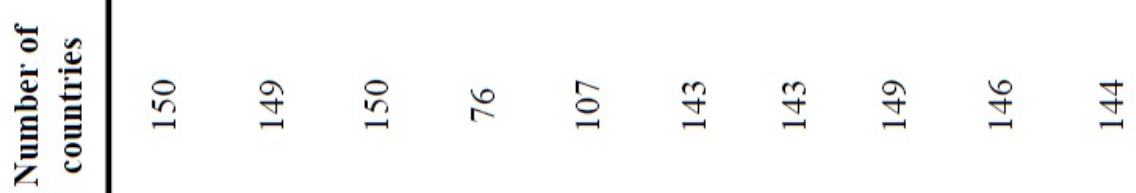

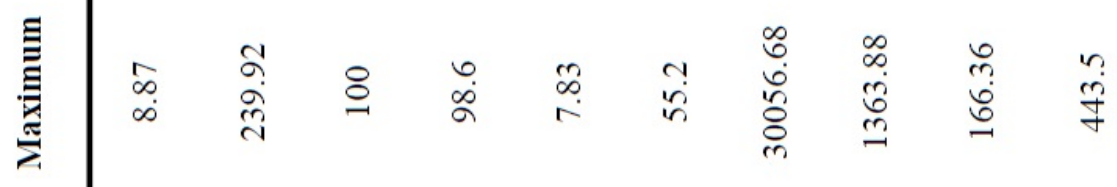

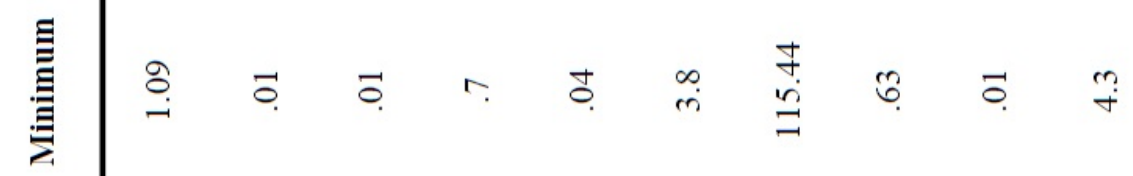

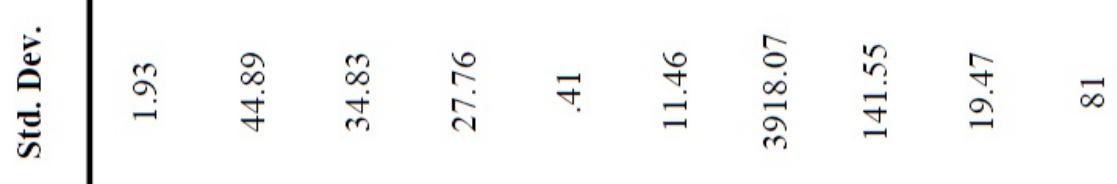

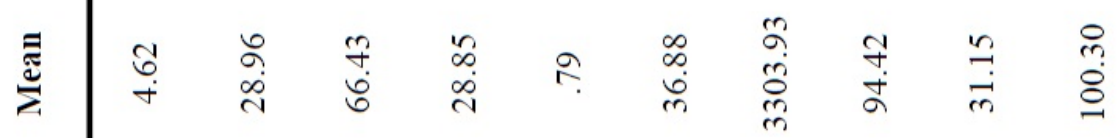

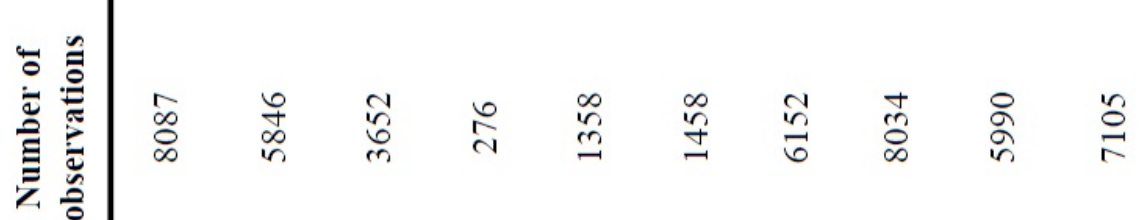

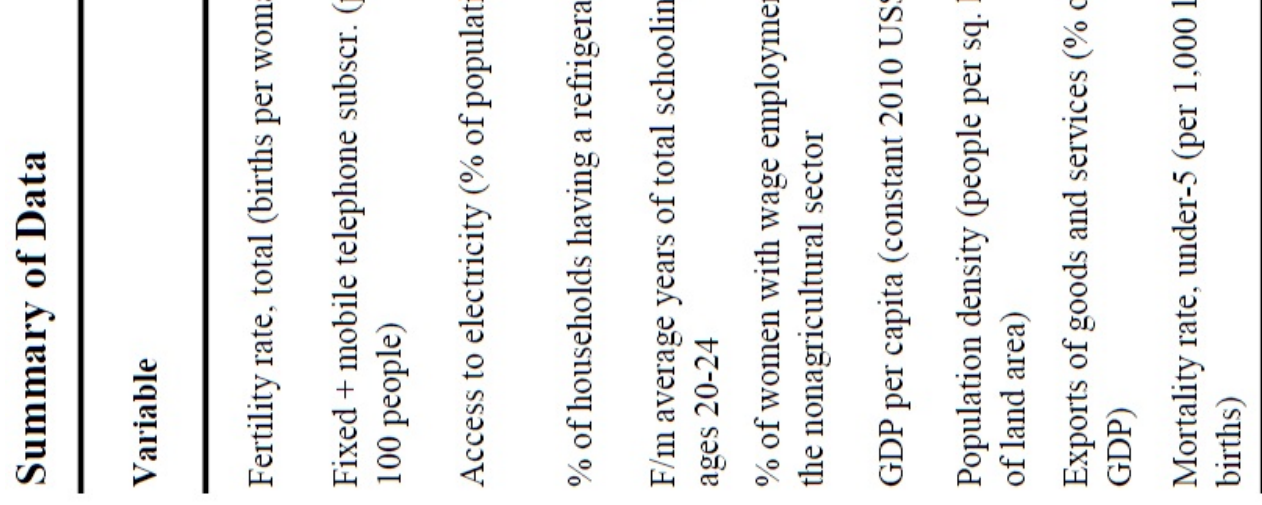


Funding: This study was funded by research grant MIS Ulysse from the Belgian F.R.S.-FNRS (grant number F. 6007.09).

Conflict of Interest: The authors declare that they have no conflict of interest.

\section{References}

1. Andres, L. et al. (2010). The Diffusion of the Internet: A Cross-Country Analysis. Telecommunications Policy 34, 323-340.

2. Ashraf, Q. and O. Galor (2011). Dynamics and Stagnation in the Malthusian Epoch. American Economic Review 101(5), $2003-2041$.

3. Bailey, M. and W. Collins (2011). Did Improvements in Household Technology cause the Baby Boom? Evidence from Electrification, Appliance Diffusion, and the Amish. American Economic Journal: Macroeconomics 3, 189217.

4. Bar, M. et al. (2018). Why did Rich Families Increase their Fertility? Inequality and Marketization of Child Care. Journal of Economic Growth 23 (4), 427 - 463.

5. Barro, R. and G.S. Becker (1989). Fertility Choice in a Model of Economic Growth. Econometrica 57, 481 - 501.

6. Barro, R. and J.W. Lee (1994). Source of Economic Growth. Caregie Conference Series on Public Policy 40, 1-46.

7. Barro, R. and J.W. Lee (2013). A New Data Set of Educational Attainment in the World, 1950-2010. Journal of Development Economics 104, 184-198.

8. Basu, K. (2006). Gender and Say: A Model of Household Behavior with Endogenously Determined Balance of Power. Economic Journal 116, 558 - 580.

9. Becker, G. S. (1960). Demographic and Economic Change in Developed Countries. Princeton University Press.

10. Becker, G.S. (1985). Human Capital, Effort, and the Sexual Division of Labor. Journal of Labor Economics 3, $33-58$.

11. Becker GS, Lewis HG (1973). On the Interaction between the Quantity and Quality of Children. Journal of Political Economy 81(2), 279-288.

12. Becker, G.S. et al. (2010). Explaining the Worldwide Boom in Higher Education of Women. Journal of Human Capital 4 (3), 203 - 241.

13. Becker, G.S. and N. Tomes (1979). An Equilibrium Theory of the Distribution of Income and Intergenerational Mobility. Journal of Political Economy 87(6), 1153 - 1189.

14. Becker, S.O. et al. (2010). The Trade-off between Fertility and Education: Evidence from before the Demographic Transition. Journal of Econ Growth 15(3), 177 - 204.

15. Becker, S.O. et al (2011). Education and Catch-up in the Industrial Revolution. American Economic Journal: Macroeconomics 3(3), 92 - 126.

16. Becker, S.O. and L. Woessman (2009). Was Weber wrong? A Human Capital Theory of Protestant Economic History. Quarterly Journal of Economics 124(2), 531 - 596.

17. Blanc, G. (2019). Modernization before Industrialization: Cultural Roots of the Demographic Transition in France. Mimeo.

18. Bloom, D.E. et al. (2009). Fertility, Female Labor Force Participation, and the Demographic Dividend. Journal of Economic Growth 14, 79 - 101.

19. Boldrin, M. and L. Jones (2002). Mortality, Fertility, and Saving in a Malthusian Economy. Review of Economic Dynamics 5, 775 - 814 . 
20. Bowden, S. and A. Offer (1994). Household Appliances and the Use of Time: the United States and Britain since the 1920s. Economic History Review 47 (4), 725 - 748.

21. Bucci, A. and K. Prettner (2020). Endogenous education and the reversal in the relationship between fertility and economic growth. Journal of Population Economics 33, 1025 - 1068.

22. Cavalcanti, T. and J. Tavares (2008). Assessing the Engines of Liberation: Home Appliances and Female Labor Force Participation. The Review of Economics and Statistics 90(1), 81-88.

23. Caldwell, J.C. (1976). Toward a restatement of demographic transition theory. Population Development Review 2, $321-366$.

24. Cervellati, M. and U. Sunde (2015). The Economic and Demographic Transition, Mortality, and Comparative Development. American Economic Journal: Macroeconomics 7(3), 189 - 225.

25. Charles, K. and M.C Luoh. (2003). Gender Differences in Completed Schooling. Review of Economics and Statistics 85(3), 559 - 577 .

26. Chiappori, P.A and Y. Weiss (2007). Divorce, Remarriage and Child Support. Journal of Labor Economics 25, $37-74$.

27. Chiappori, P.A et al. (2009). Investment in Schooling and the Marriage Market. American Economic Review 99, $1689-1713$.

28. Crafts, N. and T.C. Mills (2009). From Malthus to Solow: How did the Malthusian Economy Really Evolve? Journal of Macroeconomics 31(1), 68 - 93.

29. Cuberes D. and R. Tamura (2019). Equilibrium and A-Efficient Fertility with Increasing Returns to Population and Endogenous Mortality. R\&R at Journal of Demographic Economics, 157 - 182.

30. Dao, N.T. (2016). From Agriculture to Manufacturing: How does Geography matter? Cliometrica 10(3), 277 309.

31. Dao, N.T. and J. Dávila (2013). Can Geography lock a Society in Stagnation? Economics Letters 120, 442 - 446.

32. De la Croix, D. and M. Vander Donckt (2010). Would Empowering Women initiate the Demographic Transition in Least-Developed Countries? Journal of Human Capital 4, 85 - 129.

33. Dholakia, R. and S. Banerjee (2013). Marketing Household Durables in Emerging Markets: Empirical Evidence from India. Journal of International Marketing Strategy 1 (1), 1 - 14.

34. Diebolt, C. and F. Perrin (2013a). From Stagnation to Sustained Growth: The Role of Female Empowerment. American Economic Review: Papers and Proceedings 103 (3), 545 - 549.

35. Diebolt, C. and F. Perrin (2013b). From Stagnation to Sustained Growth: The Role of Female Empowerment. AFC Working Paper $\mathrm{N}^{\circ} 4-2013$, Association Francaise de Cliometrie.

36. Dickson el al. (1983). Consumer Acquisition Priorities for Home Appliances: A Replication and Re-evaluation. Journal of Consumer Research 9 (4), 432 - 435.

37. Doepke, M. (2004). Accounting for Fertility Decline during the Transition to Growth. Journal of Economic Growth $9(3), 347-383$.

38. Doepke, M. (2005). Child Mortality and Fertility Decline: Does the Barro-Becker Model fit the Facts? Journal of Population Economics 18, 337 - 366.

39. Doepke, M. and M. Tertilt (2009). Women's Liberation: What's in it for Men. Quarterly Journal of Economics 124 (4), 1541 - 1591.

40. Doepke, M. and M. Tertilt (2019). Does Female Empowerment Promote Economic Development. Journal of Economic Growth 24, 309 - 343.

41. Doepke, M. et al. (2012). The Economics and Politics of Women's Rights. Annual Review of Economics 4, 339 372 .

42. Dollar, D. and R. Gatti (1999). Gender inequality, Income and Growth: Are good Times for Women? Mimeograph, The World Bank, Washington DC. 
43. Duflo, E. (2012). Women's Empowerment and Economic Development. Journal of Economic Literature 50 (4), $1051-1079$.

44. Fernandez, R. (2009). Women's rights and Development. NBER Working Paper 15355.

45. Fernihough, A. (2017). Human capital and the quantity-quality trade-off during the demographic transition. Journal of Economic Growth 22, 35 - 65.

46. Galor, O. (2005). From Stagnation to Growth: Unified Growth Theory. In P. Aghion \& S. Durlauf (Eds.), Handbook of Economic Growth, 171-293. Amsterdam, North Holland

47. Galor, O. (2011). Unified Growth Theory. Princeton University Press.

48. Galor, O. (2012). The Demographic Transition: Causes and Consequences. Cliometrica 6 (1), 1 - 28.

49. Galor, O. and O. Moav (2002). Natural Selection and the Origin of Economic Growth. Quarterly Journal of Economics CXVII, 1133 - 1191.

50. Galor, O. and D.N. Weil (1996). The Gender gap, Fertility, and Growth. American Economic Review 86 (3), 374 - 387 .

51. Galor, O. and D.N. Weil (2000). Population, Technology, and Growth: From Malthusian Stagnation to the Demographic Transition and beyond. American Economic Review 90(4), 806 - 828.

52. Galor, O. and A. Mountford (2006). Trade and the Great Divergence: The Family Connection. American Economic Review 96(2), 299 - 303.

53. Galor, O. and A. Mountford (2008). Trading Population for Productivity: Theory and Evidence. Review of Economic Studies 75(4), 1143 - 1179.

54. Goldin, C. (1995). The U-Shaped Female Labor Force Function in Economic Development and Economic History. In: Schultz TP Investment in Women's Human Capital and Economic Development. University of Chicago Press, 61-90.

55. Goldin C. et al. (2006), The Homecoming of American College Women: A Reversal of the College Gender Gap. Journal of Economic Perspectives 20 (4), 133 - 156.

56. Gosling, A. 2003. The Changing Distribution of Male and Female Wages, 1978-2000: Can the Simple Skills Story Be Rejected? CEPR Discussion Paper 4045.

57. Greenwood J. et al. (2005a). Engines of Liberation. Review of Economic Studies 72, 109 - 133.

58. Greenwood J. et al. (2005b). The Baby Boom and Baby Bust. American Economic Review 95(1), 183 - 207.

59. Greenwood J. et al. (2015). Measurement without Theory, Once Again. Journal of Demographic Economics 81(3), $317-329$.

60. Greenwood, J. and A. Seshadri (2005). Technological Progress and Economic Transformation. In Handbook of Economic Growth, Volume 1B. Edited by Philippe Aghion and Steven N. Durlauf. North-Holland.

61. Hansen, G. and E. Prescott (2002). Malthus to Solow. American Economic Review 92, 1205-1217.

62. Hazan, M. and Berdugo, B. (2002). Child Labor, Fertility, and Economic Growth. Economic Journal 125, 810 828.

63. Hazan, M. and Zoabi, H. (2015a). Do Highly Educated Women Choose smaller Families? Economic Journal 125 (587), $1191-1226$.

64. Hazan, M. and Zoabi, H. (2015b). Sons or Daughters? Endogenous Sex Preferences and the Reversal of the Gender Educational Gap. Journal of Demographic Economics 81(2), 179 - 201.

65. Hazan, M. et al. (2019). Women's Liberation as a Financial Innovation. Journal of Finance 74(6), 2915 - 2956.

66. Hebden, J.J and J.F. Pickering (1974). Patterns of Acquisition of consumer durables, Oxford Bulletin of Economics and Statistics 36 (2), $67-94$. 
67. Herzer, D. et al. (2012). The Long-run Determinants of Fertility: one Century of Demographic Change 1900-1999. Journal of Economic Growth 17 (4), 357 - 385.

68. Iyigun, M. and R.P. Walsh (2007). Endogenous gender power, household labor supply and the demographic transition. Journal of Development Economics 82(1), 138 - 155.

69. Kalemli-Ozcan, S. (2002). Does the Mortality Decline Promote Economic Growth? Journal of Economic Growth 7, 411-39.

70. Kalemli-Ozcan, S. (2003). A Stochastic Model of Mortality, Fertility and Human Capital Investment. Journal of Development Economics 70(1), 103-118.

71. Kasulis et al. (1979). Consumer Acquisition Patterns for Durable Goods, Journal of Consumer Research 6 (1), 47 $-57$.

72. Klasen, S. (2002). Low Schooling for Girls, Slower Growth for All? Cross-Country Evidence on the Effect of Gender Inequality in Education on Economic Development. World Bank Economic Review 16 (3), 345-373.

73. Klasen, S. and F. Lamanna (2009). The Impact of Gender Inequality in Education and Employment on Economic Growth: New Evidence for a Panel of Countries. Feminist Economics 15 (3), 91 - 132.

74. Klasing, M.J. and P. Milionis (2020). The International Epidemiological Transition and the Education Gender Gap. Journal of Economic Growth 25 (1), $37-86$.

75. Lagerlöf, N.P. (2003). Gender Equality and Long-run Growth. Journal of Economic Growth 8 (4), 403 - 426.

76. Lagerlöf, N.P. (2006). The Galor-Weil Model revisited: a Quantitative Exercise. Review of Economic Dynamics 9 (1), 116-142.

77. Lagerlöf, N.P. (2015). Malthus in Sweden. Scandinavian Journal of Economics 117 (4), 1091 - 1133.

78. Malthus, Thomas R. (1798). An Essay on the Principle of Population. J. Johnson, London.

79. Mammen, K. and C. Paxson (2000). Women's Work and Economic Development. Journal of Economic Perspectives $14(4), 141-164$.

80. Mayers, S. and J. Sathaye (1989). Electricity Use in the Developing Countries: Change since 1970. Energy 14 (8), $435-441$.

81. McFall, J. (1969). Priority Patterns and Consumer Behavior. Journal of Marketing 33(4), 50 - 55.

82. Murphy, T.E. (2015). Old Habits die hard (sometimes). Can Département Heterogeneity tell us Something about the French Fertility Decline? Journal of Economic Growth 20 (2), 177 - 222.

83. Neher, P.A. (1971). Peasants, procreation, and pensions. American Economic Review 61(3), 380 - 389.

84. Paroush, J. (1965). The Order of Acquisition of Consumer Durables, Econometrica 33 (1), 225 - 235.

85. Soares, R. R. and B.L. Falcao (2008). The Demographic Transition and the Sexual Division of Labor. Journal of Political Economy 116(6), 1058 - 1104.

86. Tamura, R. (2006). Human Capital and Economic Development. Journal of Development Economics 79, 26-72.

87. Tamura R, et al. (2016) Black and white fertility, differential baby booms: The value of equal education opportunity. Journal of Demographic Economics 82: 27 - 109.

88. Tamura, R., and C.J. Simon (2017). Secular Fertility Declines, Baby Booms and Economic Growth: International Evidence. Macroeconomic Dynamics 21, 1601-1672.

89. Vogl, T. (2016). Differential Fertility, Human Capital, and Development. Review of Economic Studies 83, 365 401.

90. Webbink, E. et al. (2012). Hidden Child Labor: Determinants of Housework and Family Business Work of Children in 16 Developing Countries. World Development 40 (3), 631 - 642.

91. World Bank (2008). Technology and Technological Diffusion in Developing Countries, Chapter 2 in Global Economic Prospects. The World Bank, Washington D.C.

92. World Bank (2020a). "Fertility rate, total (births per woman)". Available at https://data.worldbank.org/ indicator/SP.DYN.TFRT.IN. 